\title{
Climate, Land Cover, and Bird Populations: Differential Impacts on the Future Welfare of Birders across the Pacific Northwest
}

\author{
Sonja Kolstoe, Trudy Ann Cameron, and Chad Wilsey
}

\begin{abstract}
We use a random utility model for birding destination choices based on the reports of Oregon and Washington State members of the Cornell University Laboratory of Ornithology eBird citizen science project. We estimate spatially differentiated welfare effects that birders may experience as a consequence of forecasted changes in land cover and climate. We predict per-trip welfare effects (equivalent variations) expected under a business-as-usual scenario using published forecasts for both land cover and species richness. We find significant county-level heterogeneity across eBirders in predicted average per-trip welfare effects. The results suggest discernible distributional consequences across active birders in different areas.
\end{abstract}

Key Words: biodiversity, birds, climate change, land cover, revealed preference, RUM site choice

JEL classification: Q57, Q51, Q54

\section{Introduction}

Anthropogenic influences have affected both land cover and biodiversity across the planet. The Anthropocene period, in fact, is so named to reflect humans' dominant impact on climate and the environment (Steffen, Crutzen, and

Sonja Kolstoe, Assistant Professor of Economics, Department of Economics and Finance, Salisbury University. Trudy Ann Cameron, Mikesell Professor of Environmental and Resource Economics, Department of Economics, University of Oregon. Chad Wilsey, Director of Conservation Science at National Audubon Society, National Audubon Society. Correspondence: Sonja Kolstoe Department of Economics and Finance - Salisbury University - Salisbury, Maryland - Email: shkolstoe@salisbury.edu

Our thanks to Steve Kelling at the Cornell University Laboratory of Ornithology, who generously provided the eBird data. Connie Sanchez at the Audubon Society provided the GIS data for the species presence/absence forecasts. We are grateful for the feedback from participants at the 2016 Annual Conference of the Western Economic Association International in Portland, OR and the 2017 Northeastern Agricultural and Resource Economic Association Workshop in Washington, DC. Thanks are due also to Scott Bridgham, Jill Caviglia-Harris, Dan Gleason, Christian Langpap, Ralph Mastromonaco, Will Wheeler, Greg Williams and Wesley Wilson for feedback, advice and editorial suggestions. We are also thankful to the two anonymous reviewers for their helpful suggestions. This research has been supported in part by the Raymond F. Mikesell Endowment at the University of Oregon.

Agricultural and Resource Economics Review 47/2 (August 2018) 272-310

(C) The Author(s) 2018. This is an Open Access article, distributed under the terms of the CreativeCommons Attribution-NonCommercial-NoDerivatives licence (http://creativecommons.org/ licenses/by-ncnd/4.0/), which permits non-commercial re-use, distribution, and reproduction in any medium, provided the original work is unaltered and is properly cited. The written permission of Cambridge University Press must be obtained for commercial re-use or in order to create a derivative work. 
McNeill 2007, Steffen et al. 2011; McGill et al. 2015). Human activity changes the earth's ecosystems, and changes in these ecosystems also affect human wellbeing. This research quantifies some of these feedback effects using applied welfare theory from economics to measure changes in the wellbeing of one group of recreationists-eBird members in the Pacific Northwestresulting from the effects of climate change on both land cover and the spatial distribution of bird species. Our key concern is that forecasted changes in land cover and the ranges of bird species will not be uniform across space, and thus there will be shifts in the relative attractiveness of birding destinations across the region. Birders will re-optimize in response to changes in conditions, and there may be some winners and some losers. This paper focuses on variation across space in birders' wellbeing, in the form of economic measures of the predicted equivalent variation in welfare levels associated with forecasted changes in birding opportunities.

Birds certainly adapt spatially to changes in conditions far more quickly than do plant species. This exceptional mobility affords a valuable opportunity to explore near- and short-term (the 2020s and 2050s) and spatially indexed variations in the species richness of bird populations. There have been discernible changes over time in bird species ranges and migration patterns (Pearce-Higgins, Green, and Green 2014, Langham et al. 2015, Bateman et al. 2016, US EPA 2016). Notably, Pacifici et al. (2017) find in their study that as many as one in five (of the 1,272 studied species) have experienced negative impacts of climate change in some portion of their ranges. Other studies have looked at changes in the ranges of bird species in specific countries and found similar shifts northward (e.g., Great Britain, see Thomas et al. (1999), Renwick et al. (2012)); as well movement to higher altitudes in some cases (e.g., Costa Rica, see Pounds, Fogden, and Campbell (1999)).

Of course, anthropogenic influences on wild bird populations are numerous and not limited solely to climate change. Land-use change, including urbanization and conversion of natural areas to agriculture creates steady pressure on ecosystems that support bird populations (Millennium Ecosystem Assessment 2005). Species richness and species evenness (e.g., the Shannon index, an alternative measure of bird biodiversity) both tend to decrease towards the core of an urban area, with an increasing proportion of more-resilient non-native species being seen closer to the urban center (Blair 1999, Marzluff 2001, McKinney 2002, Marzluff et al. 2016). ${ }^{1}$ The bird species best able to adapt to urban areas are those that benefit from bird feeders and ornamental plants. Species composition in these areas is based to some extent on vegetation in both yards and parks, as well as the supply of food provided in bird feeders. In rural regions, land-use change can dramatically

\footnotetext{
1 The Shannon Index considers the number of species and their relative abundance. We do not have information on how bird populations are predicted to change over time; we have only their ranges, and thus we use species richness as our measure of biodiversity for this analysis.
} 
alter the availability of natural habitats for birds and other wildlife. Conversion to agriculture, for example, continues to reduce the availability of grassland and wetland habitats in the United States (Lark, Salmon, and Gibbs 2015, Morefield et al. 2016). Climate change also has the potential to affect land cover over time as conditions change (Sohl et al. 2014).

Changes in the spatial distribution of birding opportunities across the region are of interest for their welfare effects on birders themselves, and we acknowledge that the relative attractiveness of different birding destinations is relevant when it comes to the economic impact of birding activity for nearby communities. Many towns in the region have learned that birdingrelated tourism, or avitourism, represents a non-trivial potential source of revenue for providers of food and lodging and suppliers of birding-related materials and equipment. Our paper focuses on the use of birding-related data for welfare assessment, but we acknowledge the potential for similar data sources to inform economic impact assessments to complement datagathering efforts such as the birding addendum to the National Survey of Fishing, Hunting, and Wildlife-Associated Recreation (Carver 2013).

The Literature Review section briefly describes the relevant earlier research. The Data section outlines the various datasets employed in our analysis. The Methods section sketches our approach, including our enhanced random utility maximization (RUM) model, its estimation, and our approach to the forecasting exercises in this paper, including how we calculate the expected per-trip welfare changes for birders based on our estimated model. The Estimation section briefly discusses our parameter estimates and our choice of a preferred specification. The Welfare Calculations section discusses our estimated welfare effects for these birders for a specific business-as-usual (A2 scenario) climate change scenario for the 2020s and 2050s. Lastly, we offer some conclusions and directions for future research.

\section{Literature Review}

The various impacts of climate change on several outdoor recreational activities other than birding have been considered. For example, Wall (1998) argues that the demand for some recreational activities is often greater when the weather is comfortably warm and dry. However, climate change may reduce some types of recreational opportunities. A lack of snow, for example, will limit snow sports. Loss of habitat for fish or game will limit fishing and hunting. Richardson and Loomis (2004) look at how visitation to the Rocky Mountain National Park would change and find that weather-related and resource-related variables that are considered in future climate scenarios are statistically significant determinants of respondents' contingent visitation behavior. Shaw and Loomis (2008) infer how changes in temperature, precipitation, and climate variability may affect different types of climate-sensitive recreational activities (e.g., boating, golfing, and snow sports) and predict increased participation in warm-weather activities such as boating, golfing, and beach 
recreation, and decreased participation in cold weather activities such as skiing. Dundas and von Haefen (2017) estimate the effects of climate change on shoreline fishing choices of anglers in the Atlantic and Gulf Coast regions, where they project an overall welfare gain in the Mid-Atlantic area and New England, and an overall welfare loss on the Gulf Coast.

As bird ranges shift in response to climate change, bird watchers may no longer see the same resident or migratory species that have historically been present, in different seasons, at their favorite birding sites (i.e., eBird "hotspots"). ${ }^{2}$ These losses may reflect regional declines due to displacement, or overall declines in the worldwide populations of these birds (Lundhede et al. 2014). The disappearance of species may adversely affect the utility of bird watchers in that locale and may not be offset by the new species appearing in areas where they were not previously observed. ${ }^{3}$ Both the forecasted losses and the forecasted gains in bird species may thus be relevant to our accounting of the potential costs (and/or benefits) associated with these changes.

Why might the social value of bird species richness (i.e., the number of different species present) be an issue of general interest? Bird watching is a popular recreational pursuit; roughly 20 percent of the US population considers themselves to be "bird watchers" (Carver 2013). Thus, it is important to consider how these particular recreators may be affected, as part of a thorough accounting of all the costs and benefits of climate change. It also may be prudent for policy makers to consider the potential heterogeneous distributional effects across groups of birding enthusiasts as a result of business-as-usual policies concerning climate change and land use. In broader deliberations about climate change policies, what are the distributional and equity consequences, specifically for birders, that policy makers might wish to consider?

Our research seeks to forecast only the overall net monetized changes in pertrip birder wellbeing derived from birding excursions as a result of changes in species richness and land-cover in the Pacific Northwest region of the United

\footnotetext{
2 Hotspots in eBird are publicly accessible locations that people visit regularly for birding and are suggested to eBird by eBird members. These sites undergo a review by eBird prior to being added to the list sites categorized as "hotspots."

3 Losses and gains are considered separately in Lundhede et al. (2014) in their study of willingness-to-pay (WTP) for conservation efforts in Denmark. As another illustration of the phenomenon of "loss aversion," these authors find that Danish citizens are willing to pay more to avoid the loss of a familiar and native species than they are willing to pay to gain a new species. We do not have respondents' preferences over different species and thus do not differentiate between gains and losses in this paper. The question of familiar-versus-new species merits further investigation, but will await the availability of a richer data set that can capture measurable changes in the actual composition of local bird populations over a longer period of time. The eBird dataset, upon the accumulation of several more years of data, and an additional survey on eBirders' preferences across bird species, will likely be suitable for such a study.
} 
States, under the A2 scenario (a business-as-usual climate scenario offered in the IPCC (2007) report). We address this research question using a random utility model (RUM) of destination choices for a sample of eBird citizen scientists in the Pacific Northwest. We extend the modeling framework developed in Kolstoe and Cameron (2017) to include land cover, thus making our basic model more flexible and more suitable for use to address how utility will change both directly and indirectly as a result of anticipated landcover change. ${ }^{4}$ How bird populations will be affected by climate change is related to land cover changes, because bird-range forecasts look specifically at climate suitability and habitat adaptability. ${ }^{5}$ As a consequence, it is important to include similarly modeled land cover at each birding destination as an additional distinct determinant of birders' willingness-to-pay (WTP) for a birding excursion.

Based on forecasted changes in land use and the ranges of bird species, we derive the formal utility-theoretic "equivalent variation" (EV) measure for each eBird member in the sample, assuming that (a) they consider the same lists of alternative birding destinations on each choice occasion as they did during the sample period of 2010-2012, but (b) there are changes in land cover and the spatial distributions of bird species across these destinations, due to the forecasted climate effects (specifically for the "A2" climate scenario, for the 2020s and 2050s). ${ }^{6}$ Our analysis predicts that there will be significant spatial heterogeneity across eBirders in the estimated welfare effects, including both positive and negative changes.

This paper makes the point that the prospective distributional consequences of a business-as-usual policy with respect to climate change are important, not just the overall average welfare changes across all birders. The forecasted future patterns of bird species richness and land cover differ across the region under the business-as-usual policy. Changes to birding-destination attributes drive the welfare changes in our analysis. It is important to recognize that our models of birder destination choices do not involve any detailed individual-specific sociodemographic or political ideology variables as shifters of birders' preferences. Choices across destinations are driven by the full travel cost to that destination and the attributes of the destinations themselves. Virtually

\footnotetext{
4 The bird species range changes and land cover forecasts are available for specific scenarios (A1, A1B, and A2) released in 2007 by the IPCC (2007). For a description of each of these four scenarios see Nakicenovic et al. (2000). While newer scenarios now exist that represent current state-of-the-art climate modeling, forecasts for bird ranges consistent with the updated scenarios are not available.

5 A brief summary of the broader literature regarding basic recreational demand models and avitourism can be found in Kolstoe and Cameron (2017).

6 On average, eBirders have 201 alternative birding destinations within a 60-minute drive from their home. The projections of bird species range changes are based on AOGCMs run under the A2 scenario and represent the average of the 4 GCMs used by the Langham et al. (2015) team. These were selected to represent a range of future climates: CCCMA-CGCM3.1T47, CSIRO-Mk3.0, UKMOHadCM3, NIES.
} 
all the heterogeneity in forecasted welfare effects (EVs) for birders under the business-as-usual climate scenario in this study arises from (a) differences in the spatial pattern of forecasted changes in bird species richness at the relevant set of birding destinations available to each eBirder in our sample and (b) differences in forecasted land cover changes at each destination.

\section{Data}

The eBird dataset is the product of a citizen science project built and maintained by the Cornell Lab of Ornithology. The main goal of the project is to gather data on bird populations on a year-round basis. The eBird dataset fills a niche for natural scientists who were previously limited to annual time series data from two seasonal assessments: the North American Breeding Bird Survey (BBS) in the summer, and the Audubon Christmas Bird Count (CBC) in the winter. The eBird dataset contains year-round information contributed by bird-watchers who are "members" of eBird who choose to participate by reporting their sightings to the citizen science project. The relevant portion of the dataset consists of members' trip entries, their observed birding destinations, and their volunteered residential location information. ${ }^{7}$ The eBird dataset provides information on spatially granular birding hotspots, so we are able to use this information to characterize expected conditions at each destination in a given eBirder's destination choice set. ${ }^{8}$

The destination-choice dataset for this particular paper adds land-cover data from the 2011 National Land Cover Data (NLCD) as a supplement to the data used in Kolstoe and Cameron (2017). In terms of observations, this dataset includes 1,094 trips by 221 eBirders during the sample time period of 20102012, taken to birding hotspots within 60 minutes of estimated driving time from the eBirder's home, therefore involving a total of 155,495 alternatives sites across all of these choice occasions. About 75 percent of all trips were to sites within a 60 -minute drive, and about 95 percent of all trips were to sites within 120 minutes. Unfortunately, we observe residential location information only at a single point in time-when members sign up for eBird. To minimize the risk of gross mismeasurement of travel costs because

\footnotetext{
7 The eBird dataset is rather sparse in the early years of the project (i.e., 2002-2008), so we restrict our analysis to 2010-2012 and use the prior year in each case (including 2009 for the 2010 observations), to build "expectations" based on lagged measures of species richness at each site.

${ }_{8}$ Although data-quality concerns have sometimes been raised by experts, "citizen science" data-otherwise known as volunteered geographic information (VGI) - has distinct advantages. These include the data having been generated at a finer-grained level and over a larger spatial extent than previously possible with exclusively scientific observers. To deal with data quality concerns, eBird has implemented an automated data filter to verify the validity of submitted observations by comparing the new data entry with prior data entries within close proximity, to filter out improbable sightings (Wiersma 2010). This allows eBird to guard against likely identification errors by its members and thus to maintain the integrity of the dataset.
} 
somebody has moved somewhere else in the region since they signed up for eBird, we limit the analysis to a three-year recent time window and use the more-restricted consideration set consisting of destinations within 60 minutes. ${ }^{9}$

To conform with the U.S. Fish and Wildlife's definition of a "trip away from home," we include only trips taken to a site at least one mile away from home (Carver 2013). The calculated travel costs associated with a potential birding destination take into account both distances and travel times (based on the "best route" identified by HERE Maps and MapQuest). ${ }^{10}$ Vehicle costs of travel are based on AAA's mileage fee for the respective year of the trip, multiplied by the roundtrip mileage. We count the value of travel time at roughly one-third of the average individual wage-in this case approximated using each birder's census-tract median income from the American Community Survey (ACS) converted into an hourly wage. The one-third proportion is a relatively common approximation in the literature (Fezzi, Bateman, and Ferrini 2014; Larson and Lew 2014). ${ }^{11}$

The key variable of interest in our model is the expected number of bird species, i.e., our "species richness" biodiversity measure, because we assume the primary purpose of these one-day trips is to see birds. To build this measure we use two sources of data: eBird and Birdlife International (see Ridgely et al. (2011)) to capture species that are present year round, as well as migratory species that are present at a site only for some period of time during the year. ${ }^{12}$

Table 1 provides summary statistics for the key trip variables and site attributes that represent the most important variables in our preferred models for the purposes of this analysis. ${ }^{13}$ Other control variables we include in the model are indicators for site management regimes related to biodiversity, indicators for the expected presence of an endangered bird species (state and federal listings), an indicator for whether the site lies in an

\footnotetext{
9 Note there are a total of 2,340 eligible "birding hotspot" destinations across our overall twostate area in the Pacific Northwest. Hotspots within eBird are specific and thus within a larger site, multiple "hotspots" may exist; after aggregation of such "hotspots" there are 1,860 site destinations. See the appendix and Kolstoe and Cameron (2017) for greater detail about sensitivity analyses conducted with respect to the choice of a maximal one-way travel time as the determinant of individuals' consideration sets.

10 The best route is suggested by HERE Maps, an open-source map. If a route is not available, MapQuest is queried using the Stata MQtime.ado utility described in Voorheis (2015).

11 A sensitivity analysis of the chosen fixed-wage fraction assumption is discussed in further detail in Kolstoe and Cameron (2017) and its Appendix.

12 For nonresident bird species, we use eBird data in our calculation of expected species richness (based on the different species reported at that site, in the previous year, during the same month as the current trip). For resident bird species, which are present in the area all year, we use data from Birdlife International. Greater detail on the construction of the species richness variable can be found in Kolstoe and Cameron (2017).

${ }_{13}$ Complete summary statistics for all the variables used in any model described in this paper (i.e., including other incidental control variables) are given in the Appendix in Table A1.
} 
Table 1. Descriptive statistics across all alternatives, key variables, Oregon and Washington states ${ }^{a}$

\begin{tabular}{|c|c|c|c|}
\hline Variable & Brief description & Mean & St. dev. \\
\hline $\begin{array}{l}\text { Travel cost w/time } \\
\text { cost: }\end{array}$ & $\begin{array}{l}\text { Distance }{ }^{\mathrm{b}} \text { times AAA mileage rate } \\
\text { time two (for roundtrip); using } \\
1 / 3 \text { imputed wage for Census tract }\end{array}$ & 41.10 & 17.38 \\
\hline $\begin{array}{l}\text { Difference in Median } \\
\text { Household Income } \\
(\$ 10,000)\end{array}$ & $\begin{array}{l}\text { Difference between the median } \\
\text { income in a birder's home census } \\
\text { tract and the mean of census tract } \\
\text { median incomes in WA and OR } \\
\text { (based on the 2007-2011 5-year } \\
\text { estimates at the census tract level) }\end{array}$ & 1.02 & 2.22 \\
\hline $\begin{array}{l}\text { Expected \# bird } \\
\text { species }\end{array}$ & $\begin{array}{l}\text { eBird for seasonal species, same } \\
\text { month last year; Birdlife for } \\
\text { resident species }\end{array}$ & 75.74 & 10.14 \\
\hline $\begin{array}{l}\text { 1(National Wildlife } \\
\text { Refuges) }\end{array}$ & $\begin{array}{l}\text { National Wildlife Refuges, managed } \\
\text { specifically for bird biodiversity }\end{array}$ & 0.0044 & - \\
\hline 1(National Parks, etc.) & $\begin{array}{l}\text { Permanent protection (e.g., National } \\
\text { Parks, Wilderness Areas, National } \\
\text { Wildlife Refuges) }^{\mathrm{c}}\end{array}$ & 0.036 & - \\
\hline $\begin{array}{l}\text { 1(National Forests, } \\
\text { etc.) }\end{array}$ & $\begin{array}{l}\text { Some extractive uses (e.g., National } \\
\text { Forests, State Parks, Recreation } \\
\text { Management Areas, Areas of } \\
\text { Critical Environmental Concern) }\end{array}$ & 0.27 & - \\
\hline $\begin{array}{l}\text { 1(Expect Endangered } \\
\text { Bird Species) }\end{array}$ & $\begin{array}{l}\text { Indicator that a bird species listed as } \\
\text { endangered at the federal or state } \\
\text { level is visible at a site }\end{array}$ & $8.36 \times 10^{-5}$ & - \\
\hline 1(Urban area) & $\begin{array}{l}\text { Refers to urbanized areas with } \\
>50,000 \text { people, at } 2010 \text { US } \\
\text { Census }\end{array}$ & 0.61 & - \\
\hline 1(Water) & $\begin{array}{l}\text { Includes areas of open water with } \\
\text { less than } 25 \text { percent cover of } \\
\text { vegetation and soil. This category } \\
\text { also includes areas characterized } \\
\text { by perennial cover of ice and/or } \\
\text { snow. }\end{array}$ & 0.109 & - \\
\hline 1(Planted/Cultivated) & $\begin{array}{l}\text { Includes areas of pasture, hay and } \\
\text { cultivated crops as defined in the } \\
2011 \text { NLCD }\end{array}$ & 0.097 & - \\
\hline 1(Wetlands) & $\begin{array}{l}\text { Includes areas of woody and } \\
\text { emergent herbaceous wetlands as } \\
\text { defined in the } 2011 \text { NLCD }\end{array}$ & 0.103 & - \\
\hline
\end{tabular}


Table 1. Continued

\begin{tabular}{llcc}
\hline Variable & \multicolumn{1}{c}{ Brief description } & Mean & St. dev. \\
\hline 1 (Developed) & $\begin{array}{l}\text { Includes open space and low, } \\
\text { medium and high intensity } \\
\text { developed areas as defined in the } \\
\text { 2011 NLCD }\end{array}$ & 0.412 & - \\
& & &
\end{tabular}

\footnotetext{
${ }^{a}$ Consideration sets based on 60 minute maximum travel time to alternative hotspots, 2010-2012 trips; statistics for other control variables used in our models have been relegated to the Appendix. Other controls include monthly indicators and an annual time trend in the marginal utility of E[S], four other land cover types, nine ecoregion indicators relative to the Puget Lowlands, a quadratic form in the congestion/ popularity of the destination, and interactions of the travel cost and expected species variables with a measure of the propensity (relative to the average) of this eBirder to be included in the estimating sample (221 total birders with home address information; 1,094 trips; 155,495 total alternatives; average 201 alternatives per birder (std. dev. 80.8 alternatives).

${ }^{\mathrm{b}}$ Calculated using mqtime.ado written by Voorheis (2015).

${ }^{\mathrm{c}} \mathrm{GAP}$ status 1 or 2 .

${ }^{\mathrm{d}}$ GAP status 3 .
}

urban area, indicators for the type of ecosystem at the destination, and an "expected congestion" site attribute (which is based on the share of total eBird member visits to the site in question, in the same month of the previous year). ${ }^{14}$

For our forecasts of future conditions, we augment our estimating sample with projections of avian responses to climate change using the forecasted individual-species ranges from Langham et al. (2015) and predicted changes in land use from Sohl et al. (2014). ${ }^{15}$ The indicators for land cover are used to extend the basic model, reported in Kolstoe and Cameron (2017). These variables allow us to refine the spatial resolution of the model, as well as to facilitate incorporation of land cover forecasts into our calculations of the per-trip welfare effects of climate change for birders.

\section{Datasets for Bird Population Forecasts}

We calculate forecasted future data for bird species richness at individual birding hotspots across the region using individual species distributions predicted for the 2020s and 2050s, available in the form of an existing published dataset assembled by Langham et al. (2015). This published

\footnotetext{
14 These controls follow from the preferred specification in Kolstoe and Cameron (2017).

15 We were supplied with the Audubon presence/absence GIS data with the "threshold" for presence of species for each climate scenario predetermined by the Audubon scientific team. Bioclimatic envelope models are also known as "species distribution models" because they describe the statistical relationship between the occurrence of species and a variety of variables. These models help researchers predict which areas are climate suitable for different species and which species could adapt to the future habitat in a given area. Climate suitability models use only bioclimatic variables as predictors of presence/absence of a species.
} 
dataset was generated from bioclimatic species-distribution models (i.e., climate niche models) for 588 species. Models were calibrated by relating observations from the North American Breeding Bird Survey data, as described in Sauer et al. (2013), as well as the Christmas Bird Count data, to seventeen historical bioclimatic variables. ${ }^{16}$ Models were constructed using a method known as "boosted regression trees" and employed to project the future spatial distributions of bird species under the "business-as-usual" (A2) emissions scenario across the United States and Canada, calculated at a 10$\mathrm{km}$ resolution. ${ }^{17}$ This is the most comprehensive suite of species-distribution models currently available for birds at a continental scale. The overlapping grids for each individual species can be summed across species for the region covered in our study using the Count Overlapping Polygons tool in ArcMap to yield maps of forecasted species richness. These maps can then be spatially merged to the birding hotspots in our eBird data.

The forecasted species counts can then be used to calculate a percentage change between roughly "the present" and "the future." The "present" data are forecasted for 2000-2009 using the species-range forecasting model, calibrated on historical data from 1980-1999. These forecasts are for 503 North American species (represented in the Christmas Bird Count data) and 475 species (represented in the Breeding Bird Survey). The two "future" time periods are roughly the 2020s and the 2050s. The calculated percentage changes in the expected number of bird species are depicted in the maps shown in Figure 1. Again, we rely on the closest available forecasts that are compatible with our framework, recognizing that if bird-range forecasts were to be updated to the most current central forecasts of future climate conditions, our welfare estimates would have to be adjusted accordingly.

\section{Dataset for Land Cover Forecasts}

We use the 2011 National Land Cover Database (NLCD) spatial coverages (see Homer et al. (2015) for more details about the NLCD) to characterize land cover

\footnotetext{
16 Bioclimatic variables include temperature and precipitation as well as variations in those variables that reflect seasonal differences or variation in temperature or precipitation throughout the year. These models are used to predict which species may be able to maintain viable populations in different locales, under predicted forecasts concerning climate suitability and habitat adaptability. Araújo and Peterson (2012) point out that caution must be exercised when using these models to predict species distributions, in particular with respect to the key assumptions that are required to permit the distribution of a species to be determined primarily by aspects of an area's climate (i.e., there are other variables that can also affect species distributions).

17 Richness grids are then generated by converting climatic suitability (a continuous measure produced by the boosted regression trees) into a predicted presence or absence for each species at each location by applying a species-specific threshold selected to maximize the kappa statistic, a metric of model performance that balances errors of omission and commission. Additional detail is available in Langham et al. (2015).
} 

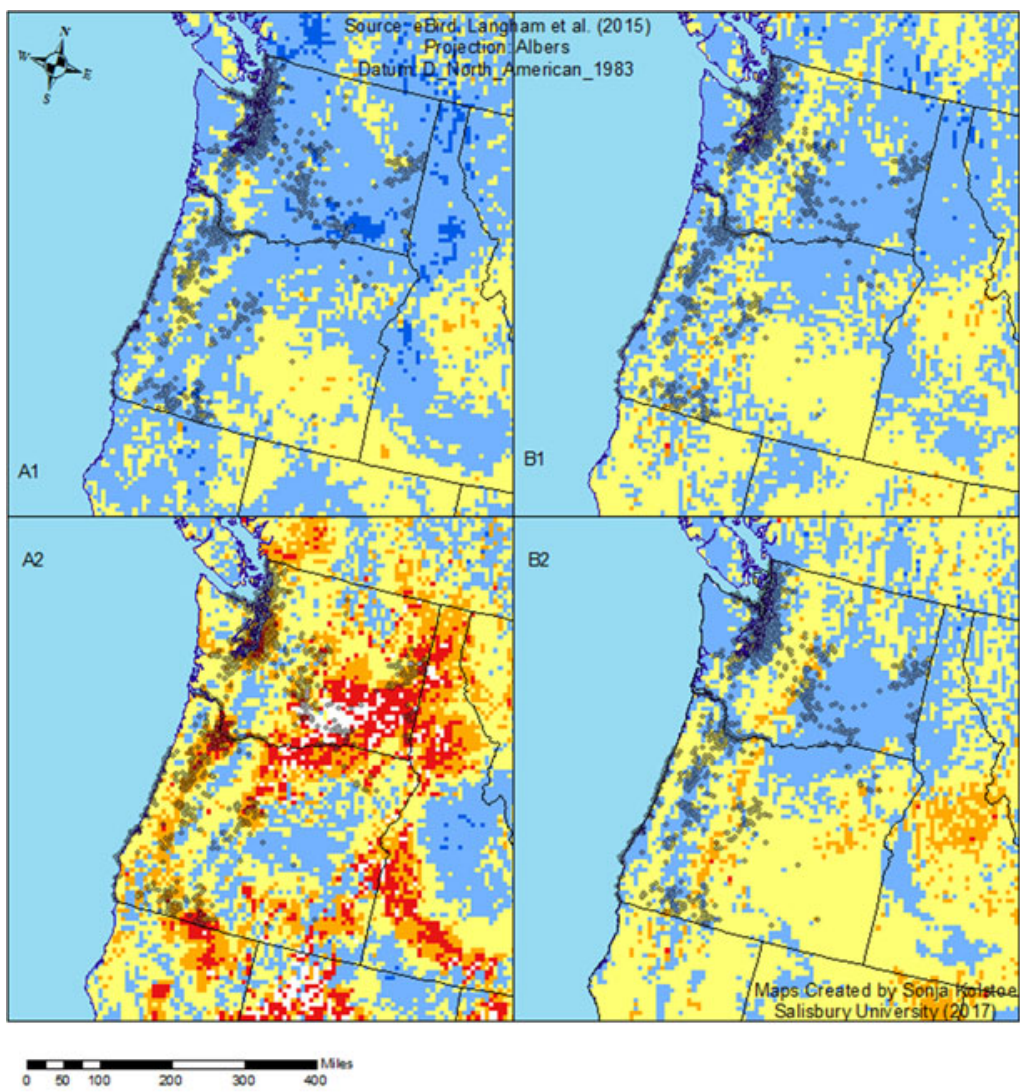

\section{Legend}

- Hotspots 2010-2012

Bird Species Richness

Forecast Change

Percent Change

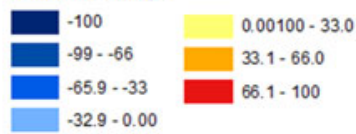

Figure 1. The data from Langham et al. (2015) provides information on forecasts of bird species distributions based on the Breeding Bird Survey (BBS) and the Christmas Bird Count (CBC). The maps above show the predicted percentage change for the baseline case of 2000 to 2020 and 2000 to 2050. The forecast is based on the A2 emission scenario, a scenario consistent with business as usual

Map A1: BBS, June, Percentage Change 2000 to 2020

Map A2: BBS, June, Percentage Change 2000 to 2050

Map B1: CBC, December, Percentage Change 2000 to 2020

Map B2: CBC, December, Percentage Change 2000 to 2050 
at all of the different birding hotspots in the region. ${ }^{18}$ The land cover classes included Water, Developed, Barren, Forest, Shrubland, Herbaceous, Planted/ Cultivated and Wetlands, as shown in Figure 2. Relative to the Developed class, Water, Planted/Cultivated and Wetlands have statistically significantly greater value to birders, so we emphasize these particular classes in our discussion in this paper. ${ }^{19}$

For projected future land cover, we use the forecasting scenarios of land-use change prepared by the USGS's EROS team corresponding to the same A2 scenario (see Sohl et al. 2014) used for our bird species range forecasts. ${ }^{20} \mathrm{~A}$ map of the current distribution of primary land cover in Oregon and Washington states is provided in Figure 2. A map of land cover overlaid with the urban area boundaries as defined by the 2010 US Census is provided in the Appendix in Figure A1 to emphasize that not all "Developed" land lies within designated urban-area boundaries, and land cover within an urbanarea boundary is not always categorized as "Developed." ${ }^{1}$

\section{Spatial Disaggregation of Welfare Effects}

We use our estimated model to assess whether any estimated positive and negative distributional consequences for birders, as a result of a business-asusual policy with respect to climate change and land cover, might differ systematically for different metropolitan areas and counties in the region. Recall that our model does not differentiate preferences by the sociodemographic characteristics or political ideology of the eBird members in this sample. Any heterogeneity in the estimated welfare effects thus stems primarily from the spatial patterns of expected changes in land cover and species richness. Given the spatial patterns in the forecasts for these two variables, it will be relevant to consider whether important subgroups of the population of eBirders (e.g., those living in different major urban areas in the region) might be differentially affected by the business-as-usual climate scenario we consider. Spatial variations in the distribution of welfare effects by county can also suggest how policy considerations might need to differ across regions.

\footnotetext{
18 The NCLD data are available at a spatial resolution of 30x30 meters and can be merged as a site attribute using the spatial join function in ArcMap 10.2.1 (Homer et al. 2015).

19 Areas classified as water include areas of open water or perennial ice and snow with less than 25 percent cover of vegetation or soil in the $30 \times 30$ meter area (Homer et al. 2015).

20 Some classes of future simulated land cover differed from NLCD classes. We have opted to harmonize these two datasets using the following rules: Areas classified as "Mechanically Disturbed" (occurring within National Forests, Other Public Lands, and Private) were reclassified as "Shrublands," and "Mining" was reclassified as "Barren."

21 The "Developed" category of land cover includes high-intensity, medium-intensity, lowintensity and open spaces, as defined in Homer et al. (2015).
} 

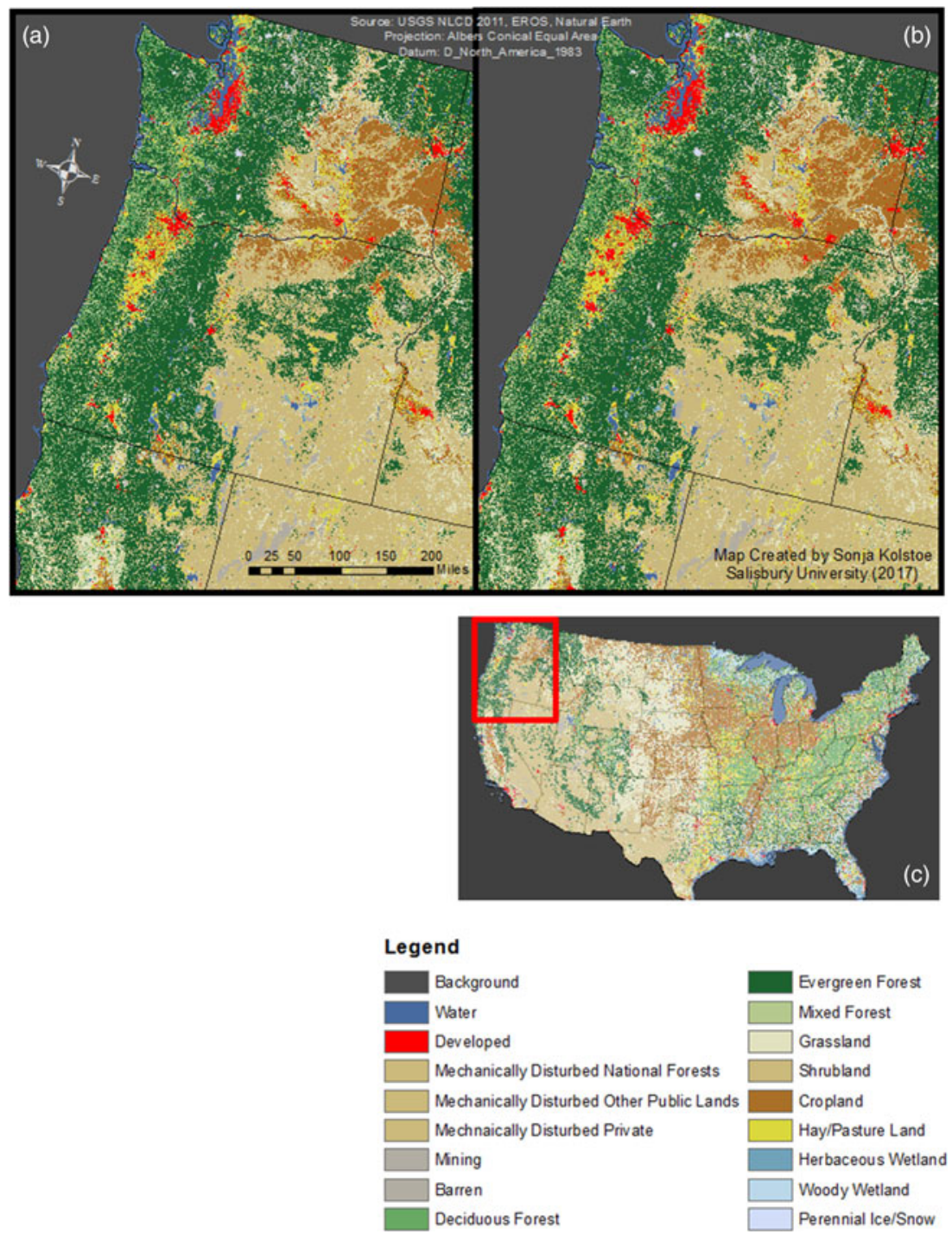

Figure 2. The forecasted land-use and land-cover for the years 2020 and 2050 under the A2 scenario. These forecasts were prepared by the USGS's LandCarbon team at the Earth Resources Observation and Science (EROS) Center for the A2 scenario using current and historical land-cover change data for the United States.

Map A uses the 2020 data, Map B uses the 2050 scenario and Map C uses the 2011 NLCD data.

The legend for the forecast data has been colored to match the legend used for the NLCD 2011 using the following aggregate classes: Water, Developed, Barren, Forest, Shrubland, Herbaceous, Planted/ Cultivated and Wetlands.

To match the NCLD 2011 data, Mechanically Disturbed is reclassified as Shrubland and Mining is reclassified as Barren. The other classes match the classes/types within the 2011 NLCD data. 


\section{Methods}

\section{RUM Model}

We use a RUM model framework and assume that $U_{j t}^{i}$ is the unobserved utility derived by birder $i$ from a trip to birding hotspot $j$ at time $t$. We assume that this indirect utility consists of a systematic component, $V_{j t}^{i}$, which can be expressed as a function of observed data and estimated parameters, and a random component that summarizes all other factors that affect utility, $\varepsilon_{j t}^{i}$. This random component is assumed to be known to the birder who is making a choice among alternative hotspots in their consideration set, but to be unknown to the researcher. The systematic component of indirect utility depends on unobserved individual household income, $Y^{i}$. The travel cost for birder $i$ to reach site $j$ is $C_{j t}^{i}$, which is assumed to be constant over time for the data used to estimate this model. ${ }^{22}$ The key birding hotspot site attributes in this analysis are the expected number of species available for viewing at the hotspot during the time period in question, $E[S]_{j t}$, and a vector of land-cover indicator variables for that hotspot, $L C_{j t}$. During the short timeframe for the trips in our estimating sample, land cover is also assumed to remain unchanged over time. We control for a vector of other site attributes for each hotspot, summarized as $A_{j t}$. The simplest version of the indirect utility function, for estimation using a conditional logit algorithm, is:

$$
U_{j t}^{i}=V_{j t}^{i}+\varepsilon_{j t}^{i}=\alpha\left(Y^{i}-C_{j t}^{i}\right)+\beta_{0} E[S]_{j t}+L C_{j t} \gamma_{1}+A_{j t} \gamma_{2}+\varepsilon_{j t}^{i}
$$

However, there may be so-called network externalities among birders. In communities where birding is more popular, the marginal utility derived from richer birding experiences may be greater if an interest in birding is shared by more of one's friends and neighbors. According to Carver (2013), birding is a more popular pastime for higher-income individuals, so we allow the marginal utility of $E[S]_{j t}$ to vary with a proxy for relative neighborhood socioeconomic status, which we capture using the difference between median income in the birder's home census tract and the average of census-tract median incomes across all census tracts in Oregon and Washington states, denoted as $\mathrm{Ydev}^{i}{ }^{23}$

\footnotetext{
22 With richer data, one might allow these costs to vary with seasonal weather conditions and driving conditions, or seasonal variations in the opportunity cost of time, but such data are not available in this context.

23 All of these census tract median incomes are drawn from the five-year American Community Survey estimates for the five-year interval ending in 2011 (i.e., collected over 2007-2011), where 2011 is the middle year of our estimating sample of birding trips during 2010-2012. Note that previously, in Kolstoe and Cameron (2017), the difference-in-median-income variable was constructed using the difference between the median income in the birder's home census tract and the average of the census tract levels of the eBirders in the sample. Here, this variable is constructed as the difference between median income and the average of census tract median
} 
Bird species richness and the types of species present at a given location will vary over the seasons, as will other unmeasured site attributes and competing recreational opportunities. Thus we allow the marginal utility of expected species richness, i.e., the coefficient $\beta_{0}$ on $E[S]_{j t}$, to vary systematically with the seasons, and to shift over time, by including interaction terms for a set of monthly indicator variables and an annual time trend (a vector of variables which we denote collectively as $T_{t}$ ). ${ }^{24}$

Finally, due to the lack of socioeconomic data on individual eBirders that might permit us to control for other systematic variations in preferences, we choose to estimate the model using mixed logit methods (outlined below). We allow the coefficient on $E[S]_{j t}$ to vary randomly across individuals according to unobservable heterogeneity by including a random component, $\mu^{\mathrm{i}}$, in that marginal utility.

The scalar $\beta_{0}$ parameter in equation (1) is therefore generalized to $\left[\left(\beta_{0}+\mu^{i}\right)+\beta_{1} \operatorname{Ydev}^{i}+\beta_{2} T_{t}\right]$. This expression for the heterogeneous marginal utility of $E[S]_{j t}$ can be distributed, across the $E[S]_{j t}$ variable that it modifies, to reveal the key interaction terms in the estimating specification: $Y \operatorname{Cev}^{i} \times E[S]_{j t}$ and $T_{t} \times E[S]_{j t}$, using our shorthand notation. ${ }^{25}$

In logit-based multiple discrete choice models such as this, it is assumed that the relative indirect utility levels of the different alternatives drive the choices made by individuals. Suppose that hotspot $m$ is designated as the numeraire alternative. ${ }^{26}$ Relative to the numeraire, indexed by $m$, the utility difference associated with alternative birding hotspot $j$ is given by:

$$
\begin{aligned}
\left(U_{j t}^{i}-U_{m t}^{i}\right)= & \alpha\left(-\left(C_{j t}^{i}-C_{m t}^{i}\right)\right)+\left[\left(\beta_{0}+\mu^{i}\right)+\beta_{1} Y \operatorname{dev}^{i}+\beta_{2} T_{t}\right]\left(E[S]_{j t}-E[S]_{m t}\right) \\
& +\left(L C_{j t}-L C_{m t}\right) \gamma_{1}+\left(A_{j t}-A_{m t}\right) \gamma_{2}+\left(\varepsilon_{j t}^{i}-\varepsilon_{m t}^{i}\right)
\end{aligned}
$$

In this way, the unmeasured individual household incomes conveniently drop out of the utility differences, so no measure of absolute income is required for

incomes across all census tracts in the region. In an earlier version of the present paper, we also considered the distributional consequences across birders of a hypothetical carbon pricing policy that would affect both travel costs and real incomes, with real-income effects differing by income level. For simulations in that case, we switched to a regionally representative baseline for current real income, exogenous to the selection of eBirders into our sample.

24 Kolstoe and Cameron (2017) found it important to allow for this temporal variation in preferences for species richness at birding destinations, although this may represent variation over time in individual birders' preferences, or a change across seasons in the composition of birders with differing motivations for birding trips.

25 We have explored whether the marginal utility of an additional bird species at a birding hotspot might also vary systematically with the type of land cover at the hotspot. We found no statistically significant differences in this marginal utility by land-cover class. However, land cover does affect, directly, the total utility derived from a given hotspot.

26 The numeraire alternative can differ across choice occasions and it is sometimes expedient to define it as the alternative that is chosen, because this alternative is clearly in the individual's consideration set on that choice occasion. 
estimation. $\mathrm{Ydev}^{i}$, again, is not a household-specific income measure. Instead, as in Kolstoe and Cameron (2017), it is merely a proxy for "approximate neighborhood relative socioeconomic status compared to the rest of the region," based on census-tract median household income in the eBirder's census tract relative to the average of this variable across all census tracts in the two-state area.

\section{Mixed Logit Estimation}

Mixed logit models are based on probabilities that individual $i$ will choose alternative $j$ on choice occasion $t$. If a specification involves both fixed and random parameters, as does our model in equation (2), we can partition the vector of coefficients to be estimated into two subsets. In what follows, let $\delta=\left(\beta_{0}+\mu^{i}\right)$ be a random parameter and let $\theta=\left(\alpha, \beta_{1}, \beta_{2}, \gamma_{1}, \gamma_{2}\right)$ remain fixed parameters. On any given choice occasion, then, the mixed logit choice probabilities are given by:

$$
P_{j t}^{i}=\int L_{j t}^{i}(\delta, \theta) f(\delta) d \delta
$$

where $L_{j t}^{i}(\delta, \theta)$ is the conventional logit probability evaluated at parameters $(\delta, \theta)$, based on the systematic portion of the utility derived from each alternative, $V_{j t}^{i}$ :

$$
L_{j t}^{i}(\delta, \theta)=\frac{\mathrm{e}^{V_{j t}^{i}}}{\sum_{k} \mathrm{e}^{V_{k t}^{i}}}
$$

and where $f(\delta)$ in equation (3) is the density function for the random parameter $\delta$. The mixed logit choice probability is thus a weighted average of the logit formula computed at different values of $\delta$, with the weights given by the density function $f(\delta)$. Tailored to our example, let $f(\delta)=\phi\left(\delta \mid \beta_{0}, \sigma_{\mu}^{2}\right)$, so that the mixed-logit probabilities are:

$$
P_{j t}^{i}=\int\left(\frac{\mathrm{e}^{V_{j t}^{i}}}{\sum_{k} \mathrm{e}^{V_{k t}^{i}}}\right) \phi\left(\delta \mid \beta_{0}, \sigma_{\mu}^{2}\right) d \delta
$$

where all of the fixed parameters $\theta$ in our model, and the random $\delta$ coefficient as well, are embedded within the expressions for $V_{j t}^{i}$ inside the large parentheses.

\section{Forecasting Per-Trip Welfare Changes Under Climate Change}

Utility derived from a birding trip, in our model, is driven almost entirely by travel costs and destination attributes. ${ }^{27}$ We wish to explore the welfare

\footnotetext{
27 This is important. We know very little about the characteristics of each eBird member in this sample, so the preference parameters that we estimate are "average" for our estimating sample.
} 
consequences of forecasted changes in the spatial distribution of expected bird species richness, along with forecasts of land cover changes across the sample region, given a business-as-usual climate forecast.

Our estimates of individual welfare change begin with the estimated utility parameters based on actual conditions, combined with the actual levels of the explanatory variables to infer the maximum attainable systematic utility level, under current conditions, across all birding destinations in the eBirder's consideration set. ${ }^{28}$ We then retain the same set of utility parameters, but permute the levels of the key explanatory variables (i.e., species richness and land cover) according to the forecasted effects of climate change on these variables. We then infer the revised maximum attainable utility level across the same set of destinations under these new conditions. The most preferred destination under the forecasted new conditions may be the same as under the actual conditions, or it may change. We do not seek to predict exactly which site will be visited under the new conditions. We seek only to infer the maximum attainable systematic utility across all destinations under the new conditions.

We monetize the before-and-after utility difference to calculate what difference in income under unchanged conditions would leave each eBirder with the same per-trip utility from birding excursions as they would obtain with the forecasted change in conditions but no other adjustment to income. Technically this dollar amount is an equivalent variation (EV). If the forecasted EV is positive, the policy in question makes the eBirder better off; if the forecasted $\mathrm{EV}$ is negative, the policy makes the eBirder worse off. ${ }^{29}$

\section{The Algebra of Per-Trip Welfare Change Calculations}

Based on our parameter values estimated in the context of utility-differences, we can revert to express the level of systematic utility, $V_{j t}^{i}$, for individual $i$, associated with a trip to hotspot $j$ in month $t$, as:

$$
\begin{aligned}
V_{j t}^{i} & =\alpha\left(Y^{i}-C_{j t}^{i}\right)+\left[\left(\beta_{0}+\mu^{i}\right)+\beta_{1} Y d e v^{i}+\beta_{2} T_{t}\right] E[S]_{j t}+L C_{j t} \gamma_{1}+A_{j t} \gamma_{2} \\
& =\alpha\left(Y^{i}\right)-\alpha\left(C_{j t}^{i}\right)+W_{j t}^{i}
\end{aligned}
$$

where the abbreviation $W_{j t}^{i}$ merely economizes on notation in what follows.

We are not able to tailor our preference parameters to capture any systematic differences by gender or age or ethnicity, for example.

28 For the trips in our sample, this may be given by the systematic utility derived from the destination actually chosen for that trip, but the error term in the random utility specification allows this not to be the case. Some other destination may offer the highest fitted systematic utility.

29 We adapt the approach described in Phaneuf and Requate $(2017$, p. 477). 
Across all of the $J_{i}$ alternative hotspots in individual $i$ 's consideration set, the "log-sum-exp" transformation, $\ln \left\{\Sigma_{k} \exp \left(V_{k t}^{i}\right)\right\}$, can be used to approximate the maximum attainable systematic indirect utility from any destination in this set of alternatives. In our model, household income does not vary across alternative destinations (birding hotspots), although travel costs do. Thus, a term $\exp [\alpha$ $\left(Y^{i}\right)$ ] (in the following equation) can be factored out of the sum over alternatives $k=1, \ldots, J_{i}$ for eBirder $i$ in the log-sum-exp expression. ${ }^{30}$

$$
\begin{aligned}
\ln \left\{\sum_{k=1}^{J_{i}} \exp \left[V_{k t}^{i}\right]\right\} & =\ln \left\{\sum_{k=1}^{J_{i}} \exp \left[\alpha\left(Y^{i}\right)-\alpha\left(C_{k t}^{i}\right)+W_{k t}^{i}\right]\right\} \\
& =\alpha\left(Y^{i}\right)+\ln \left\{\sum_{k=1}^{J_{i}} \exp \left[-\alpha\left(C_{k t}^{i}\right)+W_{k t}^{i}\right]\right\}
\end{aligned}
$$

Recall that the estimated coefficient on the travel cost variable in our conditional logit model gives $-\hat{\alpha}$ because travel cost is subtracted from the implicit income variable, $Y^{i}$.

In general, one expects some difference between the compensating variation (CV) and EV measures of the utility change associated with a change in conditions. When there are no income effects, however, these alternative measures will be the same. In our model, the indirect utility function is assumed to be additively separable in (unobserved) individual household income. Travel cost is the only money-denominated site attribute. The marginal rate of substitution between each site attribute and travel costs conveys the marginal willingness to pay for each of these attributes, which is independent of the individual birder's own household income in our specification. Relative socioeconomic status for the eBirder's neighborhood, captured crudely by our $Y_{d e v}{ }^{i}$ variable, is nevertheless allowed to shift this marginal willingness to pay.

We can simulate changes in any of the variables $W_{k t}^{i}$ in equation (6), to produce $W^{* i}{ }_{k t}$. The term includes the key expected species variable, $E[S]_{k t}$, and the land cover indicators, $L C_{k t}$, for our climate change simulations. The per-trip equivalent variation, $E V_{t}{ }_{t}$ can be calculated using the following formulas (adapted from p. 283 of Freeman, Herriges, and Kling (2014)):

\footnotetext{
30 In nested logit models the log-sum-exp of the indirect utilities associated with the subset of alternatives on a particular branch is termed the "inclusive utility value" or simply the "inclusive value" for that particular subset of alternatives. In that case, likewise, it is approximately the maximum attainable utility across that subset of alternatives.
} 


$$
\begin{aligned}
E V_{t}^{i} & =\frac{1}{\alpha}\left\{\ln \left[\sum_{k=1}^{J_{i}} \exp \left[V_{k t}^{* i}\right]-\ln \left[\sum_{k=1}^{J_{i}} \exp \left[V_{k t}^{i}\right]\right]\right\}\right. \\
& =\left(\Delta Y^{i}\right)+\frac{1}{\alpha}\left\{\ln \left\{\sum_{k=1}^{J_{i}} \exp \left[-\alpha\left(C_{k t}^{* i}\right)+W_{k t}^{* i}\right]\right\}\right. \\
& \left.-\ln \left\{\sum_{k=1}^{J_{i}} \exp \left[-\alpha\left(C_{k t}^{i}\right)+W_{k t}^{i}\right]\right\}\right\}
\end{aligned}
$$

when preferences are linear in net income, for scenarios where there is no (predictable) change in the level of real income, it is moot whether income (i.e., the budget constraint) is measured annually, monthly, or over some other time period. Income drops out of the utility difference entirely. This accounts for the expedience of the common assumption that preferences are linear and additively separable in the net income, $Y^{i}-C_{k t}^{i}$, associated with each alternative.

The log-sum-exp function yields an approximation to the largest of the exponentiated terms in the sum in question. In this utility-theoretic context, this largest term corresponds to the highest attainable utility across the consideration set. This may not always be the destination actually chosen in each case, because of the random component in the utility function, but it is the destination with the largest predicted utility. In equation (8), then, the identity of the destination predicted to yield the highest utility in the estimation sample will depend on the characteristics of each destination, summarized as its corresponding $W_{k t}^{i}$ term. The identity of the destination predicted to yield the highest utility in the forecast period will depend on the forecasted characteristics for each destination, summarized by its corresponding $W^{* i}{ }_{k t}$ term. In this case, the real costs of travel are assumed to remain unchanged, so the $-\alpha\left(C^{* i}{ }_{k t}\right)$ term remains the same. Our EV measure thus monetizes the difference in maximum attainable utility level across all destinations in the choice set, as a consequence of spatially explicit forecasts for changes in land cover and bird species distribution.

In this paper, we do not seek to predict changes in the expected numbers of trips to birding destinations in different areas. With larger samples and richer data, it should be possible also to use models such as these to help forecast which birding destinations are likely to see more visitors and which may see fewer, with implications for changes in the economic impact of birding activity on local economies. Given the limitations of the current sample, we seek only to estimate per-trip welfare effects, rather than to develop a comprehensive model for the overall numbers of trips to each destination. 


\section{Estimation Results}

\section{Recreational Site Choice}

Consideration sets: We assume that the consideration set for each respondent includes the selected birding hotspot on each choice occasion plus the typically huge number of other possible hotspots within 60 minutes of travel time from the individual's home address. ${ }^{31}$

Our models indicate that $\sigma_{\mu}^{2}$, the estimated variance of $\beta_{0}$ (the random coefficient on the expected species richness variable), is statistically significantly different from zero. Thus mixed logit specifications are preferred over the analogous fixed-coefficient conditional logit specifications. Selected parameter estimates are shown in Table 2, for key site attributes and controls. The full estimation results are provided in Appendix Table A2.

Systematic sample selection corrections: The estimated coefficients in Table 2 pertain to an eBird member with average propensity to appear in our estimating sample (i.e., one having the average propensity to have provided home address information to eBird). This inference is appropriate because we allow both the coefficient on the travel cost variable and the baseline coefficient on the expected species variable to vary systematically with the fitted propensity from a separate probit model designed to explain home address provision across all eBird members in Washington and Oregon states. ${ }^{32,33}$

\section{Marginal Utilities of Travel Costs $\left(C_{\mathrm{jt}}\right)$ and Expected Species Richness $\left(E[S]_{\mathrm{jt}}\right)$}

The four columns of results in Table 2 begin by reproducing the parameter estimates for the preferred specification from Kolstoe and Cameron (2017).

\footnotetext{
31 This designation of "consideration sets" is consistent with the approach taken in Kolstoe and Cameron (2017). Sensitivity analyses with respect to this number of minutes are reported in the Appendix in Table A3. These analyses show that the coefficient on the $\operatorname{Ydev}^{i} \times E[S]_{j t}$ interaction term can change sign and statistical significance. For example, when 90-minute travel-time consideration sets are used, as reported in the Appendix in Table A4, this coefficient becomes statistically insignificant. We have opted to feature results for the conservatively defined choice sets that are consistent with the site choices of eBirders based on the travel times (and therefore distances) of their actual trips.

32 Let $D A P^{i}$ be the individual's deviation from the mean propensity to supply address information. Our models thus specify our two key coefficients as: $\alpha^{\prime}=\alpha+\pi_{1} D A P^{i}$ and $\beta_{0}^{\prime}=$ $\beta_{0}+\pi_{2} D A P^{i}$. The "selection correction" coefficients $\pi_{1}$ and $\pi_{2}$ can be found at the bottom of Table 2. We attempt no correction to the variance-covariance matrix for the estimated parameters as a consequence of the estimated nature of the $D A P^{i}$ variable.

33 Estimation of the coefficients in Table 2 is accomplished using the mixlogitado utility for Stata. Note that the standard errors in these specifications are not clustered by individual. Cameron and Miller (2010) argue that in the presence of group-specific fixed effects, one cannot compute cluster-robust standard errors. For the mixed logit random-parameter models featured in the body of the paper, we instead bootstrap the standard errors using 500 Halton draws (Train 2009).
} 
Table 2. Progression of models, pooled Oregon and Washington sample; Key coefficients

\begin{tabular}{|c|c|c|c|c|}
\hline Variable: coefficient & $\begin{array}{l}\text { (1) Ecological } \\
\text { Economics } \\
\text { Specification }\end{array}$ & $\begin{array}{c}\text { (2) Site } \\
\text { Attributes }+ \\
\text { Land Cover }\end{array}$ & $\begin{array}{c}\text { (3) }+ \text { Ecoregions, } \\
\text { Preferred } \\
\text { Specification }\end{array}$ & $\begin{array}{c}\text { (4) }+\mathbf{1}(\mathrm{LC} \\
\text { Developed) } \\
\times \mathbf{1}(\text { Urban Area) } \\
\end{array}$ \\
\hline \multicolumn{5}{|l|}{ Travel cost variable } \\
\hline Roundtrip, $1 / 3$ wage: $\alpha$ & $\begin{array}{c}-0.0362^{* * *} \\
(0.00306)\end{array}$ & $\begin{array}{c}-0.0365^{* * *} \\
(0.00301)\end{array}$ & $\begin{array}{c}-0.0363^{* * *} \\
(0.00306)\end{array}$ & $\begin{array}{c}-0.0362^{* * *} \\
(0.00306)\end{array}$ \\
\hline \multicolumn{5}{|l|}{ Expected species richness: $E[S]_{j t}$} \\
\hline$E[S]_{j t}$ random coef. Mean: $\beta_{0}$ & $\begin{array}{c}0.0105 \\
(0.0127)\end{array}$ & $\begin{array}{c}0.0109 \\
(0.0123)\end{array}$ & $\begin{array}{c}0.00949 \\
(0.0123)\end{array}$ & $\begin{array}{c}0.00954 \\
(0.0123)\end{array}$ \\
\hline$E[S]_{j t}$ random coef. Variance: $[\sigma]_{\mu}$ & $\begin{array}{r}0.0219 * * \\
(0.00869)\end{array}$ & $\begin{array}{r}0.0194^{* *} \\
(0.00887)\end{array}$ & $\begin{array}{r}0.0195^{* *} \\
(0.00873)\end{array}$ & $\begin{array}{r}0.0195^{* *} \\
(0.00876)\end{array}$ \\
\hline$E[S]_{j t} \times$ dev. Med. H. Inc. $(\$ 10,000): \beta_{1}$ & $\begin{array}{c}0.00512^{*} \\
(0.00274)\end{array}$ & $\begin{array}{c}0.00472 * \\
(0.00267)\end{array}$ & $\begin{array}{c}0.00470^{*} \\
(0.00266)\end{array}$ & $\begin{array}{c}0.00471^{*} \\
(0.00266)\end{array}$ \\
\hline \multicolumn{5}{|l|}{ Land cover: LC } \\
\hline 1(LC Water/Perennial Snow \& Ice): $\gamma_{1,1}$ & - & $\begin{array}{l}0.394^{* * *} \\
(0.107)\end{array}$ & $\begin{array}{l}0.377^{* * *} \\
(0.107)\end{array}$ & $\begin{array}{l}0.458^{* * *} \\
(0.147)\end{array}$ \\
\hline 1(LC Planted/Cultivated): $\gamma_{1,2}$ & - & $\begin{array}{l}0.221^{* *} \\
(0.113)\end{array}$ & $\begin{array}{c}0.208^{*} \\
(0.114)\end{array}$ & $\begin{array}{c}0.283^{*} \\
(0.148)\end{array}$ \\
\hline 1(LC Wetlands): $\gamma_{1,3}$ & - & $\begin{array}{l}0.390^{* * *} \\
(0.106)\end{array}$ & $\begin{array}{l}0.372^{* * *} \\
(0.106)\end{array}$ & $\begin{array}{l}0.457^{* * *} \\
(0.149)\end{array}$ \\
\hline $1($ LC Developed $) \times 1($ UrbanArea $): \gamma_{1,4}$ & - & - & - & $\begin{array}{c}0.133 \\
(0.162)\end{array}$ \\
\hline
\end{tabular}


Table 2. Continued

\begin{tabular}{|c|c|c|c|c|}
\hline Variable: coefficient & $\begin{array}{l}\text { (1) Ecological } \\
\text { Economics } \\
\text { Specification }\end{array}$ & $\begin{array}{c}\text { (2) Site } \\
\text { Attributes }+ \\
\text { Land Cover }\end{array}$ & $\begin{array}{c}\text { (3) }+ \text { Ecoregions, } \\
\text { Preferred } \\
\text { Specification }\end{array}$ & $\begin{array}{c}\text { (4) }+\mathbf{1}(\mathrm{LC} \\
\text { Developed) } \\
\times \mathbf{1}(\text { Urban Area })\end{array}$ \\
\hline \multicolumn{5}{|l|}{ Other site attributes: $A_{j}, A_{j t}$} \\
\hline \multirow[t]{2}{*}{1 (National Wildlife Refuge): $\gamma_{2,1}$} & $0.899^{* * *}$ & $0.788^{* * *}$ & $0.793^{* * *}$ & $0.789 * * *$ \\
\hline & $(0.185)$ & $(0.189)$ & $(0.192)$ & $(0.192)$ \\
\hline \multirow[t]{2}{*}{ 1(National Parks, etc.): $\gamma_{2,2}$} & $0.737^{* * *}$ & $0.769^{* * *}$ & $0.736^{* * *}$ & $0.727^{* * *}$ \\
\hline & $(0.125)$ & $(0.125)$ & $(0.128)$ & $(0.128)$ \\
\hline \multirow{2}{*}{1 (National Forests, etc.): $\gamma_{2,3}$} & $0.379^{* * *}$ & $0.420^{* * *}$ & $0.409^{* * *}$ & $0.407^{* * *}$ \\
\hline & $(0.0746)$ & $(0.0761)$ & $(0.0765)$ & $(0.0765)$ \\
\hline \multirow[t]{2}{*}{ 1(Expected Endangered Bird Species): $\gamma_{2,4}$} & $1.674^{*}$ & $1.900^{* *}$ & $1.842^{* *}$ & $1.853^{* *}$ \\
\hline & $(0.854)$ & $(0.845)$ & $(0.864)$ & $(0.867)$ \\
\hline \multirow[t]{2}{*}{1 (Urban Area): $\gamma_{2,5}$} & $-0.651^{* * *}$ & $-0.551^{* * *}$ & $-0.567^{* * *}$ & $-0.603^{* * *}$ \\
\hline & $(0.0789)$ & $(0.0826)$ & $(0.0843)$ & $(0.0954)$ \\
\hline Sample Selection? & Yes & Yes & Yes & Yes \\
\hline Time fixed effects & Yes & Yes & Yes & Yes \\
\hline Ecoregion indicators? & Yes & No & Yes & Yes \\
\hline Total Alternatives & 155,495 & 155,495 & 155,495 & 155,495 \\
\hline Log Likelihood & -4605.94 & -4603.77 & -4590.51 & -4590.16 \\
\hline AIC & 9279.89 & 9271.54 & 9263.01 & 9264.32 \\
\hline BIC & 9618.34 & 9590.08 & 9671.14 & 9682.41 \\
\hline
\end{tabular}

Standard errors in parentheses. ${ }^{* * *} \mathrm{p}<0.01,{ }^{* *} \mathrm{p}<0.05,{ }^{*} \mathrm{p}<0.1$

Notes: Estimates estimated via STATA mixlogit.ado. These results use 500 Halton draws for the mixed logit model simulations. Baseline coefficient represents the marginal utility for an eBirder who has the average propensity of eBird members to have given their home address information at the time of registration and is visiting a rural site that is not managed for biodiversity in the Puget Lowland in January of 2012. Models are the results for choice sets within a 60-minute drive from a member's home. 
We then provide a sequence of three increasingly general mixed-logit specifications focusing on ecoregions and the new land-cover variables. Model 2 documents what happens when we simply substitute the land-cover indicators, with their greater spatial resolution, for the original coarser set of ecoregion controls used in Model 1. Whether we control for ecosystem differences makes no real qualitative difference to the key marginal utilities of travel cost or expected species. Nevertheless, we restore the ecosystem indicators in Models 3 and 4 because some of them bear individually statistically significant coefficients. ${ }^{34}$

In Model 3, our preferred specification, the land-cover class indicators are included simply as site attributes with "main" effects on the utility derived from a birding hotspot. ${ }^{35}$ The complete results for this model are available in Appendix Table A2. Model 4 shows that the interaction term between the "Developed" land-cover class (the baseline category) and urban area is statistically insignificant. We explored the inclusion of this interaction term out of a concern about the breadth of the "Developed" category, and in recognition of the fact that not all developed areas lie within designated urban area boundaries (see Appendix Figure A1). Given this result, we retreat to Model 3 as a sufficiently general model for eBirder preferences.

Travel costs: $C_{j t}^{i}$. For our willingness-to-pay calculations, the marginal utility of other consumption (i.e., the negative of the $\alpha$ coefficient on the travel cost variable in a linear specification) serves as the denominator, so this travelcost coefficient is very important. The results in Table 2 demonstrate that the coefficient on the travel cost variable is strongly significantly different from zero, with the expected sign. Its magnitude is also very robust across all of our specifications. All else equal, birders are more likely to visit nearby birding hotspots.

Expected species richness: $E[S]_{j t}$. We are particularly interested in the marginal utility of our species richness (biodiversity) measure, represented by the expected number of different bird species at each destination based on the previous year's data for the same site in the same month. The baseline for the marginal utility of the expected number of species consists of the mean of the random parameter, $\beta_{0}$, but there is evidence of statistically significant unobserved heterogeneity across eBirders, because the variance in this random parameter, $\sigma_{\mu}^{2}$, is statistically significant across all specifications in Table 2.

\footnotetext{
34 Also, a likelihood ratio test of the set of restrictions imposed by Model 2, against the moregeneral Model 3, rejects the null hypothesis that the coefficients on the set of ecoregion indicators are simultaneously zero.

35 We have explored interacting the different land cover classes with expected species. However, these interactions were not statistically significant. This may be due to a lack of statistical power, given the current number of observations.
} 
The single mean coefficient $\beta_{0}$, however, also applies only when we are considering an eBirder who lives in a census tract with median income equal to the average of these median incomes across all census tracts in the region, so that $Y \operatorname{dev}^{i}=0$. Our crude sample selection correction also shifts this marginal utility, so the baseline coefficient also applies specifically for an eBird member having an average propensity to report home address information and thus to be included in our sample. Furthermore, given the seasonal variation and trend in this marginal utility, the baseline coefficient, $\beta_{0}$, also applies specifically for the month of January in the year 2010. January is one of the least appealing months in which to go birding in this region, so it is unsurprising that in this month, the estimated marginal utility for an additional bird species is statistically indistinguishable from zero. In June and December however, the more popular months for birding and the two seasons for which we have specific forecasts of species ranges under climate change, the baseline marginal utility for an additional expected species is statistically significantly positive, as evidenced in the set of coefficients on the eleven month-specific interaction terms reported in Appendix Table A2. The marginal utility of an additional expected species also increases with the deviation of the eBirder's census-tract income from the mean in the region. Members from more-affluent areas have a statistically significantly greater marginal utility for an additional expected species in all seasons, on average.

Land-cover classes: This is the key information that is new to the models in this paper, and along with species richness, crucial for the effects of climate change on eBirder welfare levels that we seek to forecast. Among the landcover classes, the baseline "Developed" class can range from open space to high-intensity, as defined in the NLCD 2011. Relative to that category, the subset of land-cover classes for which marginal utility is statistically different are Water, Planted/Cultivated and Wetlands. All these land-cover types typically support greater biodiversity and are more conducive to bird watching. The land-cover types that provide the highest relative utility are Water and Wetlands, and these land-cover types are what one might expect to find in some of the region's National Wildlife Refuges, all of which are managed for bird biodiversity and may be a more aesthetically pleasing setting for a bird watching trip. ${ }^{36}$ Based on the estimates in Table 2, relative to the "Developed" land-cover class, eBird members derive statistically significantly greater utility from trips to hotspots that are characterized as Water, Planted/Cultivated and Wetlands. Population growth, climate change and development pressures are likely to alter/diminish the quality of at least some of these types of birding hotspots.

\footnotetext{
36 The "Water" class includes open water which is defined as "areas of open water, generally with less than $25 \%$ cover of vegetation or soil" (Homer et al. 2015). The Wetland class includes woody wetlands and emergent herbaceous wetlands.
} 
Other site attributes: In all of the models reported in Table 2, we also control for a variety of site attributes and include indicators for the prior presence of endangered or threatened bird species, different ecological management regimes, an expected congestion/popularity measure, land-cover type, and the type of ecoregion. The coefficients on the subset of site attributes which were also included in the models in Kolstoe and Cameron (2017) remain statistically significant and of a similar magnitude and sign. For this reason, the estimated coefficients on many of these other attributes are relegated to Appendix Table A2.

To summarize, the coefficient on the site-level indicator for the prior presence of an endangered bird species is positive and statistically significant, suggesting that a significant marginal utility premium exists for sites where one might expect to see an endangered bird species. Also, the coefficient on the indicator for sites that are managed specifically for biodiversity (National Parks, Wilderness Areas, etc.) is statistically larger in magnitude than the coefficient on the indicator for sites less-managed for biodiversity (National Forests, etc.) where extractive activities such as logging or mining are allowed. This difference may also reflect that National Parks, Wilderness Areas, etc. tend to be iconic in some way, which may explain why there is a premium on TWTP for trips to such places, regardless of their bird populations. There is an additional premium for destinations that are managed specifically for bird biodiversity (National Wildlife Refuges). This designation often coincides with the land-cover classes that bear the largest positive and statistically significant utility premiums relative to the baseline ("Developed") land-cover class. These estimated differences seem intuitively plausible-a trip to a more-pristine area yields higher utility than a trip to a less-pristine area, independent of the number of bird species expected to be seen.

We continue to find that our prior-year congestion/popularity measure confers diminishing marginal utility. The linear coefficient on the congestion/ popularity variable is positive and the coefficient on the squared term is negative. This suggests that there may exist a threshold at which a site's popularity begins to reduce people's utility, possibly as a result of congestion. If birding is a social activity, and a destination is not too crowded, additional visitors do not seem to diminish the quality of the experience. It is possible that at low levels, a little congestion is a "good" thing.

We continue to include ecoregions, as systematic shifters of utility, to avoid omitted variable bias, the utility that an individual may derive from the type of destination (i.e., ecological factors) may be separate from the incremental utility associated with the expected number of bird species at that destination. Ecoregions will also be correlated to some extent with the distance of a hotspot from the major population centers in the region, and we do not wish to bias the key travel cost coefficient by omitting this potentially relevant determinant of utility. Given the diverse array of land-cover classes within any large ecoregion, we are not worried about extreme collinearity 
among these two groups of indicators. There is certainly a strong likelihood that land-cover class and ecoregion indicators will be correlated with expected numbers (and types) of species present, so it is important to allow for independent effects on utility levels for all three factors. Some birders choose their birding destinations because certain hotspots have other attractive features (e.g., scenery) besides just the number of expected bird species. In our complete set of estimation results in the Appendix, the omitted landcover class is "Developed" and the omitted ecosystem is the Puget Lowlands in Washington State. Relative to that baseline, positive and statistically significant differences in utility are found for the ecoregions designated as the Willamette Valley, the Cascades and the Coast Range.

\section{Welfare Calculations}

\section{Actual Conditions: TWTP and MWTP by Selected Site Attributes}

Under current conditions, and for the estimated utility parameters reported for Model 3 in Table 2 (our preferred specification), we calculate the effects on total willingness to pay (TWTP) for a birding excursion of (a) the key species richness variable (shown in Table 3), (b) month-of-year/season (shown in Table 4), and (c) land-cover class at the destination (shown in Table 5). Our approach is to establish an arbitrary baseline case, and then to permute the factor in question and report the resulting effect on our willingness-to-pay measures relative to that benchmark case. The relevant baseline case is summarized in the title for each table. ${ }^{37}$ This strategy allows us to illustrate the extent of the influence of each factor on the implied total willingness to pay (TWTP) for a birding excursion and, in the case of month-of-year/ seasonal effects in Table 4 on marginal willingness to pay (MWTP) for an additional expected species at the destination. The basic results in Tables 3 and 4 are similar to those obtained for our earlier models without land-cover indicators, in the corresponding tables in Kolstoe and Cameron (2017). ${ }^{38}$

Table 5 provides the key estimation results that are entirely new with the specification in this paper. We use the full set of parameter estimates for land-cover classes to show the extent of variation in the implied total willingness to pay for a benchmark birding trip, based solely on differences in land-cover classes. The point estimate of TWTP is about $\$ 276$ for the

\footnotetext{
37 We rotate through a complete set of site attributes in Appendix Table A6.

38 The variance of the random parameter is again strongly statistically significant, suggesting there remains considerable unobserved heterogeneity in the marginal utility of species richness across the sample. It is possible that the size of the variance of this coefficient might vary systematically with some potentially observable eBird member characteristic(s), but we leave this inquiry for future work.
} 
Table 3. Relationship between the value of a birding trip and species richness at the destination (calculated at mean congestion level, for June 2012, unmanaged site, no endangered species reported, nonurban developed destination in the Puget Lowlands)

\begin{tabular}{lcc}
\hline Simulation & \$ Total WTP (for trip) & \$ Marg WTP (per species) \\
\hline 5 species (minimum) & $32.05^{* * *}(24.18,40.72)$ & $3.43^{* * *}(1.99,4.95)$ \\
69 species (10th percentile) & $251.64^{* * *}(151.95,356.91)$ & $"$ \\
72 species (25th percentile) & $261.93^{* * *}(157.92,371.83)$ & $"$ \\
78 species (50th percentile) & $282.52^{* * *}(169.89,401.58)$ & $"$ \\
81 species (75th percentile) & $292.81^{* * *}(175.88,416.45)$ & $"$ \\
84 species (90th percentile) & $303.10^{* * *}(181.87,431.31)$ & $"$ \\
98 species (maximum) & $351.14^{* * *}(209.79,500.69)$ & $"$
\end{tabular}

Note: Across 10,000 draws from the joint distribution of the parameter estimates, mean and 5th and 95th percentiles of the simulated sampling distribution for calculated WTP. Interval reflects the precision of the parameter estimates.

baseline class of land cover ("Developed," which includes open areas as well as low-intensity, medium- intensity and high-intensity developed areas). This TWTP rises as high as $\$ 286$ for sites where the land cover is Water or for sites where the land cover is Wetlands. Recall that only the utility differentials for Water, Planted/Cultivated, and Wetlands are individually statistically significant. For Water and Wetlands, the TWTP differential is estimated to be about $\$ 10$ per trip. The TWTP differential for Planted/ Cultivated is about half that.

Our implied total willingness to pay of $\$ 276$ applies for a trip during the prime bird-watching season (in June) to a site with our baseline characteristics. This addition of the land-cover attribute makes the model more usable for conservation purposes when looking at how land-cover changes are likely to affect birders' welfare levels. This TWTP estimate is within the range found by Zawacki, Marsinko, and Bowker (2000) of $\$ 18.70$ $\$ 327.50$ for a more-general wildlife watching trip. Our TWTP estimate is higher than that found by Dissanayake and Ando (2014), who report upon a stated-preference survey to assess the value of grassland restoration (where bird biodiversity and density were included as site attributes). They find a TWTP between \$75-\$150. However, our estimates of TWTP for a birding trip vary dramatically over the course of a year in our Pacific Northwest context, as documented in Table 4-from essentially \$0 in February to \$276 during the peak of the breeding season in June. Our estimate of TWTP for a birding excursion in December, the second most popular birding month in the Pacific Northwest, is only $\$ 134$, which is consistent with the estimates of Dissanayake and Ando (2014). 
Table 4. Systematic seasonal variations in the value of a birding trip (calculated at mean species richness and mean congestion level, for June 2012, unmanaged site, no endangered species reported, nonurban developed destination in the Puget Lowlands)

\begin{tabular}{lcc}
\hline Simulation & \$ Total WTP (for trip) & \$ Marg. WTP (per species) \\
\hline January & $41.70\left(0^{\mathrm{a}}, 85.26\right)$ & $0.34(-0.23,0.92)$ \\
February & $0.48(0,0)$ & $-0.70^{* *}(-1.24,-0.20)$ \\
March & $55.17^{*}(1.87,110.08)$ & $0.52(-0.18,1.25)$ \\
April & $59.01^{*}(1.38,117.38)$ & $0.57(-0.18,1.34)$ \\
May & $51.97^{*}(3.48,101.68)$ & $0.48(-0.16,1.14)$ \\
June - BBS & $275.77^{* * *}(165.96,391.83)$ & $3.43^{* * *}(1.99,4.95)$ \\
July & $29.06(0,76.85)$ & $0.14(-0.50,0.81)$ \\
August & $88.31^{* *}(23.60,154.79)$ & $0.96^{*}(0.12,1.84)$ \\
September & $98.72^{* *}(20.14,180.42)$ & $1.10^{*}(0.07,2.17)$ \\
October & $68.95^{*}(12.16,127.17)$ & $0.71(-0.04,1.46)$ \\
November & $124.64^{* * *}(45.20,206.70)$ & $1.44^{* *}(0.39,2.52)$ \\
December - CBC & $134.25^{* * *}(58.31,214.59)$ & $1.57^{* * *}(0.58,2.62)$ \\
\hline
\end{tabular}

Note: Across 10,000 draws from the joint distribution of the parameter estimates: mean and 5th and 95th percentiles of the simulated sampling distribution for WTP. Interval reflects precision of the parameter estimates. BBS, Breeding Bird Survey; CBC, Christmas Bird Count. Relative to omitted month of January, only the indicators for February June, November, and December bear statistically significant coefficients in Model 3.

${ }^{\mathrm{a}}$ When a given draw produces a negative value for calculated TWTP, we interpret these values as zero, because it is not possible to pay a negative amount for a trip. For MWTP, however, negative marginal utilities for a particular attribute are possible, in principle, so we do not censor MWTP estimates at 0 .

\section{Forecasted Policy: Business-as-Usual Climate Change}

We can use our model of birder preferences to predict what may happen to the per-trip welfare of birders in this region if conditions were to match the business-as-usual (A2 per IPCC (2007)) climate scenarios for the 2020s and 2050s. More than 1000 trips across the seasons during our sample period are used to produce our utility parameter estimates, but there are correspondingly fewer trips any given month. We use the species-range forecasts estimated for June based on the USGS Breeding Bird Survey (BBS) data, and for December based on the Audubon Christmas Bird Count (CBC). ${ }^{39}$ No forecasts are available specifically for each month in 2020s and 2050s, unfortunately, so we must improvise as follows.

\footnotetext{
39 The BBS runs from the end of May through the beginning of July. The CBC runs from midDecember through the beginning of January.
} 
Table 5. Variations in the value of a birding trip by type of land cover at the destination (calculated at mean species richness and mean congestion level, for June 2012, unmanaged site, no endangered species reported, nonurban destination in the Puget Lowlands)

\begin{tabular}{lcc}
\hline Simulation & \multicolumn{1}{c}{ \$ Total WTP (for trip) } & \$ Marg WTP (per species) \\
\hline Developed (baseline) & $275.77^{* * *}(165.96,391.83)$ & $3.43^{* * *}(1.99,4.95)$ \\
Water & $286.17^{* * *}(176.58,402.75)$ & $"$ \\
Planted/Cultivated & $281.52^{* * *}(172.03,397.30)$ & $"$ \\
Wetlands & $286.11^{* * *}(175.87,402.73)$ & $"$ \\
\hline
\end{tabular}

Note: Across 10,000 draws from the joint distribution of the parameter estimates: mean and 5th and 95th percentiles of the simulated sampling distribution for WTP. Interval reflects precision of the parameter estimates. Relative to the omitted category of Developed, only the indicators for Water, Planted/Cultivated, and Wetlands bear statistically significant coefficients in Model 3. Full set of results in Appendix in Table A5.

Our utility model is based upon birding excursion data from throughout the year, but our two projections of avian species richness each apply only one season. Therefore, we treat the two available percentage-change projections for each birding hotspot as different predictions applying to the entire year in each of our two future time periods (the 2020s and the 2050s). The BBS and CBC forecasts are somewhat different. We use the summer-based BBS forecast, and the winter-based CBC forecast, to put rough bounds on what may happen year-round (see Figure 1). ${ }^{40}$ These two cases should provide a crude picture of the types of welfare changes that are possible, based on the available forecasted data for changes in the ranges of bird species and changes in land cover. ${ }^{41}$

40 We calculate these percentage changes by summing the counts of species present at each birding hotspot based on GIS data for individual species ranges-both for the baseline of 2000s (which we must assume is similar enough to the relevant period for our eBird trips), and as forecasted for the 2020s and 2050s based on the A2 scenario. Figure 1 provides maps showing the percentage changes for these two future years, for the forecasted BBS and the CBC species absence/presence counts. White areas in Figure 1 correspond to areas of no data from these Audubon forecasts. Our welfare change calculations omit observations at sites with no forecasted data for these the calculations.

${ }^{41}$ Another necessary caveat is that the willingness to pay estimates in Tables 3 through 5 are for one specific trip. The reported dispersions in the estimates reflect the asymptotically normal joint distribution in the estimated utility parameters, rather than heterogeneity across different trips. There is one "observation" for each random draw from the joint distribution of the parameters. In this section, in contrast, we employ a cruder approach, using only the point estimates for each parameter, combined with the explanatory variables for every trip in our sample (either actual, or forecasted for the future policy scenarios). The reported distributions reflect the variation across trips in the equivalent variation estimates due to the different travel costs, relative socioeconomic status and destination attributes for all alternatives in the individual's 
Relative to our estimating sample of eBirder preferences for 2010-2012 in this region, Table 6 summarizes the main results for our forecasted nearterm (2020) and somewhat longer-term (2050) per-trip welfare changes (measured as equivalent variations, EV). Each set of results includes the average EV across all of the trips in the sample, the standard deviation in these EVs, as well as the minimum and maximum predicted EVs. Notably, each range includes both positive and negative values, implying that there will be both winners and losers among the eBird members in our sample, with changes in land cover and the ranges of bird species and thus in species richness at different hotspots.

The two columns in Table 6 summarize the distributions of welfare changes, across the trips in our estimating sample, for 2020 and 2050. Within horizontal Panel A of this table, and in each of the two sub-sections of horizontal Panel B, forecasted EVs are provided for separate species richness projections based first on the data from the Breeding Bird Surveys (BBS) conducted in the May-June period, and then on the data from the Christmas Bird Counts (CBC) conducted in the December-early January period. Again, we scale the entire year's species richness forecast according to these two benchmarks, to give a sense of the differences.

Panel A in Table 6 summarizes the welfare effects for the entire sample of eBirders, across all of their birding excursions. The key take-away point is that there is a lot of heterogeneity in the welfare changes across the sample. This heterogeneity stems solely from the forecasted changes in species richness and land cover across the birding hotspots in each person's consideration set. Given that almost every person has a different consideration set, the eBirders in our sample will be affected differently by climate change. For example, consider the results based on the CBC forecast for 2050. At one extreme, climate change is forecasted to result in a loss of per-trip welfare, for some eBirder in our sample, on the order of $\$ 109$ (based on the BBS forecast for 2050). At the other extreme, climate change is forecasted to result in a gain in welfare, for some (different) eBirder in our sample, on the order of $\$ 106$. Again, these forecasts assume the same people take trips at the same time of year and choose from the same consideration sets-but when they re-optimize under new conditions, they do not necessarily choose the same destination from that consideration set. If we forced people to continue to go to the same destination under different conditions, their maximum attainable welfare would be lower than if they can re-optimize.

Panel B in Table 6 disaggregates, subsetting the data to show the corresponding distributions for just the Seattle metropolitan area and for just the Portland/Vancouver metropolitan area (excluding the rural areas of the 
Table 6. Distribution across our sample of birding trips, for per-trip equivalent variation calculated from parameter point estimates only; simulated for spatially differentiated forecasted changes in region-wide land cover and bird species richness. KEY: Across our sample of trips: average per-trip EV (std. dev. in per-trip EV), [minimum per-trip EV, maximum per-trip EV]

2020s

$2050 s$

A. Entire sample
1. BBS (May-June)
0.44 (3.67)
$-8.94(14.77)$
2. CBC (December-January)
$[-43.49,63.20]$
$[-109.35,38.57]$
$-1.65(5.30)$
$[-47.95,57.17]$
$[-50.18,106.14]$

B. By major metropolitan area

(a.) Seattle metro area

1. BBS (May-June)

$0.46(3.54)$

$-9.08(13.65)$

$[-43.49,3.34]$

[-109.35, 22.60]

2. CBC (December-January)

-1.16 (4.53)

$-2.13(5.52)$

$[-47.95,4.26]$

$[-50.18,5.72]$

(b.) Portland, OR \& Vancouver, WA metro area

1. BBS (May-June)

$1.06(0.88)$

$-9.02(17.06)$

$[-2.34,3.93]$

$[-66.35,27.13]$

2. CBC (December-January)

$-1.93(5.20)$

$1.56(1.24)$

$[-19.55,9.08]$

$[-1.08,8.50]$

Notes: Forecasts (1) and (2) assume the same predictions about land cover, but differ according to whether the Breeding Bird Survey (BBS) or the Christmas Bird Count (CBC) is used as the basis for predicted changes in bird species richness in the 2020s and 2050s.

two states). There is no striking difference in the average welfare derived from birding excursions in these two metropolitan areas, and there remains considerable heterogeneity within each metropolitan area (see Figures A2-A5 in the Appendix).

Table 6 reveals that to look only at the means of our EV estimates across these coarse partitions would ignore some potentially important finer-scale distributional consequences. Again, the extent to which individual eBirders are affected by the forecasted changes in land cover and bird species richness depends on how conditions change at those sites included in each individual eBirder's consideration set of birding hotspots. Consideration sets vary with the residential location of the birder in question. On average across all eBirders in our sample, the point estimates of EV per trip are relatively small. 
However, given that the range in EV estimates is sometimes very large, it may be important to think about finer spatial resolution in the patterns of welfare effects from changes in land cover and bird species richness across different areas in the Pacific Northwest.

\section{County-Level Spatial Patterns in Forecasted Welfare Effects}

The so-called "efficiency" criterion that underlies benefit-cost analysis in economics does not automatically take into account the often equally important "equity" consequences of proposed policies. ${ }^{42}$ In recent years, especially in the context of environmental policy assessment, researchers have been increasingly sensitive to the potential distributional consequences of proposed policies. These distributional consequences are at the foundation of the issue of "environmental justice" or "environmental equity" from the perspective of economics.

The models of eBirder preferences that we estimate in this paper involve very limited heterogeneity according to the identity of the individual birder. The closest thing we have to the sociodemographic characteristics of individual birders is the median household income for the census tract in which the birder resides, relative to the mean of these median incomes across all census tracts in this two-state area. Beyond this heterogeneity stemming from likely relative socioeconomic status, preferences are implicitly averaged across all birders in the estimating sample and do not differ by gender, age, or ethnicity (some sociodemographic characteristics along which environmental justice assessments are sometimes considered). The main way in which the policies we consider lead to differences in the EV associated with any given policy is via the location of the birder's place of residence relative to shifting spatial patterns in the populations of birds and in land cover within about an hour's drive from the person's home.

Our final exercise is to disaggregate our forecasted welfare changes for eBirders by county, across this two-state region. In the two panels of Figure 3, we depict spatial patterns in the EV associated with business-asusual with respect to climate change in the 2050s, with the associated changes in land use and bird populations for both June (based on the BBS data forecasts) and December (based on the CBC data forecasts). To emphasize relative welfare changes, the dark-to-light shading (for counties for which our eBird sample includes data) reflects only the deciles of the distribution of EV forecasts under the BBS and the CBC forecasts for species ranges. Negative values are denoted in parentheses, and we do not force the same scale across the two maps.

\footnotetext{
42 Efficiency requires only that the gains to the winners outweigh the losses to the losers, without considering the identities of prospective winners and losers.
} 
(a)

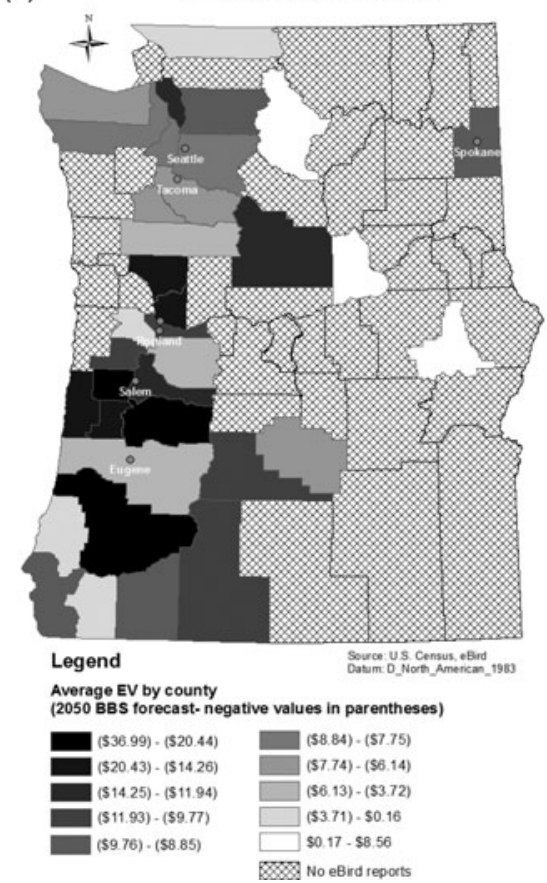

(b) $\quad \mathrm{EV}$ for $\mathrm{CBC} 2050$ Scenario

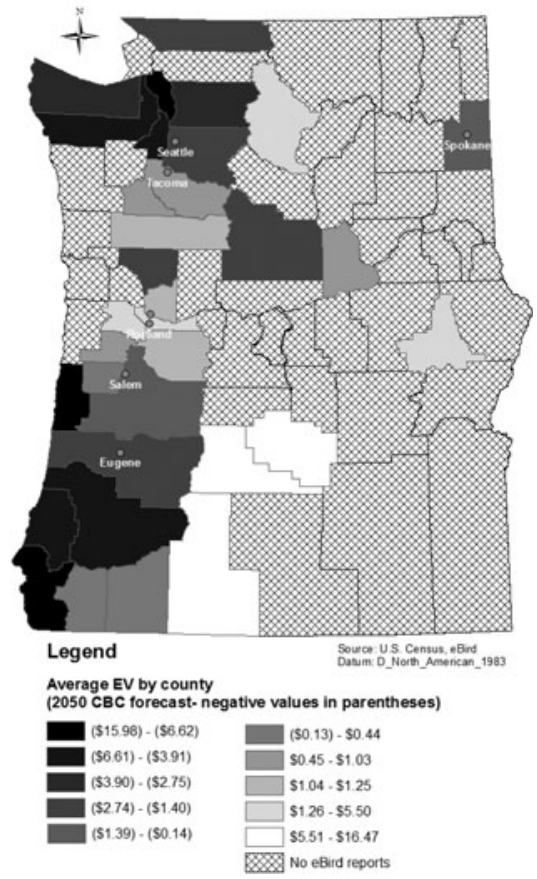

Figure 3. By policy: Deciles of the distribution of county average per-trip equivalent variation (darker $=$ more negative). (a) EV for BBS 2050 Scenario (b) EV for CBC 2050 Scenario

The fundamental take-home point concerns the unequal spatial distribution of the losses (or gains) in per-trip welfare for eBirders as a consequence of the changes in land cover and bird ranges predicted to result under the A2 business-as-usual climate forecast. Each of these two maps, independently, confirms that the consequences of climate change for birder welfare are different across counties. Given how parsimonious are our specifications, the results in Figure 3 should be taken as confirmation that even with essentially identical preferences, there can be differences in the welfare effects from policies simply because of differences in the spatial distribution of birding destination options relative to where people live and differences in the way that climate change is expected to affect bird populations and land cover across these different sets of destinations.

\section{Caveats}

Our estimates for per-trip equivalent variations for birding excursions under climate change completely ignore any "non-use" or "passive use" values 
derived from land cover and bird populations (e.g., existence, option, or bequest values) that might be associated with a business-as-usual climate policy. Also, the utility derived from backyard birding is likely to be sizeable. Backyard birding is not being considered at all in this study, and birders may substitute away from birding excursions and toward back-yard birding (or vice-versa) as the spatial distribution of bird species richness changes. Significant changes in local bird populations can likewise be expected to result in welfare changes from backyard birding as well as from away-from-home birding excursions, so it may be unwise to think about only the per-trip welfare effects for birding excursions away from home. ${ }^{43}$ As with most types of economic forecasts, some maintained hypotheses underlie our calculations of the welfare effects discussed in this paper:

- All other factors affecting birding preferences and destination choices remain unchanged;

- The consideration sets of eBirders, basically a radius based on travel time from their place of residence, will be unaffected by changes in land cover or climate;

- The same types of eBirders (e.g., avidity levels) will continue to live at roughly the same residential locations, despite changes in land cover and climate;

- Each eBirder's number of trips per year will not change substantially in response to changes in land cover, climate and bird populations, although their most-preferred destinations in their choice sets may change;

- Any attempt to scale per-birder average per-trip EV estimates to the entire population of birders must be tempered by recognition that eBirders are likely a non-random subset of all birders in the region and may be more avid than the average member of the general population. Furthermore, not everyone is a birder, and some subset of the population may be completely unaffected by changes in land use and bird populations.

Climate-change-related effects on bird ranges are already being observed. However, our research suggests that changes in land cover also have an additional important direct effect for the utility that people derive from birding excursions, independent of its effects on bird occurrence. It would be difficult to tease out the overall effect of land cover on birder utility given that this factor is also bound up with its influence on future bird populations.

\footnotetext{
43 In ongoing research, we are attempting to measure the welfare effects of prospective changes in backyard birding opportunities as a result of climate change and other prospective polices, so a fuller comparison may be possible when those results are available.
} 
The results of our welfare analyses suggest that, across our sample of eBirders in different locations throughout the Pacific Northwest, there will be winners and losers as the ranges of different bird species in this region continue to shift northward or to higher elevations. These results also assume, in our bare-bones specification, that eBirders value each bird species identically. This may not be the case, but richer data and larger samples will be required to permit us to discriminate reliably between preferences across different types of species. Also, the results of Lundhede et al. (2014) suggest the negative welfare effects from the loss of a familiar bird species may not be offset exactly by the gain of a new bird species, and the potential for "loss aversion" is not captured by our specifications based mostly on a simple biodiversity measure such as species richness.

\section{Conclusions and Directions for Further Research}

In the Pacific Northwest U.S., many local economies have seen a dramatic decline in extractive industries such as commercial forestry. These communities have actively sought ways to replace this declining industry, and several have learned that they have a comparative advantage in birdingrelated tourism. The geographic locations of these communities lie along the main flyway for numerous species of migrating wild birds, so that seasonal events such as birding festivals can be designed to draw new types of visitors who will add to the demand for food and lodging and birding-related goods and services. ${ }^{44}$

As climate change and land-cover changes affect bird populations, though, there will be changes in the types of birds that will be available for viewing during these festivals. Our endeavor, in this work, is to provide a somewhat better picture of the benefit currently enjoyed by birders, derived from species richness among wild bird populations across the region and in different seasons. These benefits dictate the demand for opportunities to view wild birds and have the potential to affect the economic impact from birding-related tourism in the area.

The main contribution of this paper is to illustrate how citizen science data from eBird can be used to compare the potential welfare effects, for birders who travel to see wild birds, of the forecasted effects of climate and development on land cover and bird populations. Maintaining the status quo at zero cost, unfortunately, is not an option. The illustrative forecasts in this

\footnotetext{
44 In some resource-based communities in this region, many people took a dim view of "environmentalists" because of the displacement created by logging restrictions designed to protect endangered species such as the spotted owl. There is now considerably more enthusiasm with the realization that non-consumptive "use" of wild bird populations by avid birders can bring considerable replacement revenue to the area. See, for example http://www. klamathbirdingtrails.com/events/index.shtml.
} 
paper reveal that business as usual with respect to land cover and climate is likely to have spatially heterogeneous welfare effects. The existing literature, which provides a limited number of examples of values for specific birding sites and iconic bird species under current conditions, offers little assessment of potential future welfare impacts to be expected from land-cover change or climate change in this domain. ${ }^{45}$

The data on birding trips used for this analysis are somewhat limited, and represent only a sample of convenience with very little information on the eBirders themselves, other than the origin point for their reported birding trips. It would be helpful to differentiate birder preferences by gender, age, ethnicity and household income levels, for example. Despite its minimal birder characteristics, the analysis demonstrated in this paper provides useful insights about the types of future studies that could potentially be conducted. With a larger data set, over a wider region (with more birding trips by more eBird members), it would be valuable to explore whether the welfare effects of a wider variety of conservation policies might vary, not just on the fine spatial scale identified in this paper, but also by type of bird, rather than just uniformly over all species. It may be appropriate, with richer data, to refine the approach in this paper also to allow for variation in the marginal utility of species richness by type of bird and/or by another biodiversity index that take species abundance into account (such as a Shannon or Simpson index).

It will also be important to develop a method to consider the representativeness of the eBird sample, both with respect to the entire population of birders, and with respect to the population as a whole. For policies that might increase utility from birding activities, it would be helpful to develop a method of modeling the number of birding trips per person, and the number of people who choose to engage in birding activities at all. Birding trip data constitute what economists call "revealed preference" data, where people are observed to incur real costs to gain access to an environmental good. But we suspect that bird populations are also valued highly by a lot of people who do not take trips away from home specifically to see birds. Backyard birding is popular, but backyard birding is more difficult to model, because no travel behavior is observed and the researcher must be more resourceful in

\footnotetext{
45 In an earlier version of this paper, we also explored the potential welfare consequence for eBirders in this region of an aggressive carbon pricing policy of $\$ 200$ per ton. If this policy allowed land use and bird populations to remain at the status quo, the effects on eBirder welfare would have been felt through changes in the cost of travel to each alternative birding destination and effects on the real incomes of these birders, which are forecasted to differ by income bracket. A carbon pricing program would likewise affect the net income associated with each destination in the individual's consideration set, and changes in relative (real) incomes across the region (different for different income quartiles) would change the marginal utility of additional expected bird species. The equivalent variations for these changes were almost universally negative. Of course, this is not an indictment of carbon pricing. Many other avoided climate-change damages would figure into a full benefit-cost analysis.
} 
gathering data about tradeoffs that people are willing to make with respect to local bird populations. We are currently developing in a separate "stated preference" study that seeks to measure the value of bird biodiversity among people who do not travel away from home specifically to see birds.

Managers of citizen science projects may appreciate that the data they collect to monitor bird populations can be used to model the benefits to humans derived from these populations, but this can be done well only if sufficient information is collected about each citizen scientist. Citizen science projects typically focus primarily on the behavior of the species being observed. Environmental economists are interested, instead, in the behavior of the species (i.e., homo sapiens) that is doing the observing.

\section{Supplementary material}

The supplementary material for this article can be found at https://doi.org/10. 1017/age.2018.9

\section{References}

Araújo, M.B., and A.T. Peterson. 2012. "Uses and Misuses of Bioclimatic Envelope Modeling." Ecology 93(7): 1527-1539.

Bateman, B.L., A.M. Pidgeon, V.C. Radeloff, J. VanDerWal, W.E. Thogmartin, S.J. Vavrus, and P.J. Heglund. 2016. "The Pace of Past Climate Change vs. Potential Bird Distributions and Land Use in the United States." Global Change Biology 22(3): 1130-1144.

Blair, R.B. 1999. "Birds and Butterflies along an Urban Gradient: Surrogate Taxa for Assessing Biodiversity?" Ecological Applications 9(1): 164-170.

Cameron, A.C., and D.L. Miller. 2010. Robust Inference with Clustered Data. No. 10, 7. Working Papers, University of California, Department of Economics.

Carver, E. 2013. Birding in the United States: A Demographic and Economic Analysis Addendum to the 2011 National Survey of Fishing, Hunting, and Wildlife-Associated Recreation. Technical report. Available at https://digitalmedia.fws.gov/cdm/ref/ collection/document/id/1874 (accessed October 2014).

Dissanayake, S.T., and A.W. Ando. 2014. "Valuing Grassland Restoration: Proximity to Substitutes and Trade-Offs among Conservation Attributes." Land Economics 90(2): 237-259.

Dundas, S.J., and R.H. von Haefen 2017. "Weather Effects on the Demand for Coastal Recreational Fishing: Implications for a Changing Climate." Working Paper.

Fezzi, C., I.J. Bateman, and S. Ferrini. 2014. "Using Revealed Preferences to Estimate the Value of Travel Time to Recreation Sites." Journal of Environmental Economics and Management 67(1): 58-70.

Freeman, A.M., J.A. Herriges, and C.L. Kling. 2014. The Measurement of Environmental and Resource Values: Theory and Methods. New York: RFF Press Routledge.

Homer, C., J. Dewitz, L. Yang, S. Jin, P. Danielson, G. Xian, J. Coulston, N. Herold, J. Wickham, and K. Megown. 2015. "Completion of the 2011 National Land Cover Database for the Conterminous United States-Representing a Decade of Land Cover Change Information." Photogrammetric Engineering and Remote Sensing 81(5): 345-354.

IPCC. 2007. "The Fourth Assessment Report of the Intergovernmental Panel on Climate Change." Geneva, Switzerland. 
Kolstoe, S., and T.A. Cameron. 2017. "The Non-Market Value of Birding Sites and the Marginal Value of Additional Species: Biodiversity in a Random Utility Model of Site Choice by EBird Members." Ecological Economics 137: 1-12.

Langham, G.M., J.G. Schuetz, T. Distler, C.U. Soykan, and C. Wilsey. 2015. Conservation Status of North American Birds in the Face of Future Climate Change. PLoS ONE 10(9): e0135350.

Lark, T.J., J.M. Salmon, and H.K. Gibbs. 2015. "Cropland Expansion Outpaces Agricultural and Biofuel Policies in the United States." Environmental Research Letters 10(4): 044003.

Larson, D.M., and D.K. Lew. 2014. "The Opportunity Cost of Travel Time as a Noisy Wage Fraction." American Journal of Agricultural Economics 96(2): 420-437.

Lundhede, T.H., J.B. Jacobsen, N. Hanley, J. Fjeldså, C. Rahbek, N. Strange, and B.J. Thorsen. 2014. "Public Support for Conserving Bird Species Runs Counter to Climate Change Impacts on Their Distributions." PLoS ONE 9(7): e101281.

Marzluff, J.M. (2001). Worldwide Urbanization and its Effects on Birds. In Avian Ecology and Conservation in an Urbanizing World, pp. 19-47. Boston: Springer.

Marzluff, J.M., B. Clucas, M.D. Oleyar, and J. DeLap (2016). "The Causal Response of Avian Communities to Suburban Development: A Quasi-Experimental, Longitudinal Study". Urban Ecosystems 19(4): 1597-1621.

McGill, B.J., M. Dornelas, N.J. Gotelli, and A.E. Magurran (2015). Fifteen Forms of Biodiversity Trend in the Anthropocene. Trends in Ecology \& Evolution 30(2): 104-113.

McKinney, M.L. 2002. "Urbanization, Biodiversity, and Conservation: The Impacts of Urbanization on Native Species are Poorly Studied, but Educating a Highly Urbanized Human Population about These Impacts Can Greatly Improve Species Conservation in All Ecosystems." Bioscience 52(10): 883-890.

Millennium Ecosystem Assessment. 2005. "Ecosystems and Human Well-Being: Biodiversity Synthesis." Report, World Resources Institute. Available at https://www.millennium assessment.org/documents/document.354.aspx.pdf (accessed March 2014).

Morefield, P.E., S.D. LeDuc, C.M. Clark, and R. Iovanna. 2016. Grasslands, Wetlands, and Agriculture: The Fate of Land Expiring from the Conservation Reserve Program in the Midwestern United States. Environmental Research Letters 11(9), 094005.

Nakicenovic, N., J. Alcamo, A. Grubler, K. Riahi, R. Roehrl, H.-H. Rogner, and N. Victor. 2000. Special Report on Emissions Scenarios (SRES), A Special Report of Working Group III of the Intergovernmental Panel on Climate Change. Cambridge, UK: Cambridge University Press. Available at http://pure.iiasa.ac.at/id/eprint/6101/ (accessed April 2015)

Pacifici, M., P. Visconti, S.H. Butchart, J.E. Watson, F.M. Cassola, and C. Rondinini. 2017. Species/'Traits Influenced Their Response to Recent Climate Change. Nature Climate Change 7(3): 205-208.

Pearce-Higgins, J.W., R.E. Green, and R. Green. 2014. Birds and Climate Change: Impacts and Conservation Responses. Cambridge, UK: Cambridge University Press.

Phaneuf, D.J., and T. Requate. 2017. A Course in Environmental Economics: Theory, Policy, and Practice. New York, NY: Cambridge University Press.

Pounds, J.A., M.P. Fogden, and J.H. Campbell. 1999. "Biological Response to Climate Change on A Tropical Mountain." Nature 398(6728): 611-615.

Renwick, A.R., D. Massimino, S.E. Newson, D.E. Chamberlain, J.W. Pearce-Higgins, and A. Johnston. 2012. "Modelling Changes in Species' Abundance in Response to Projected Climate Change." Diversity and Distributions 18(2): 121-132.

Richardson, R.B., and J.B. Loomis. 2004. "Adaptive Recreation Planning and Climate Change: A Contingent Visitation Approach." Ecological Economics 50(1): 83-99.

Ridgely, R., T. Allnutt, T. Brooks, D. McNicol, D. Mehlman, B. Young, J. Zook, and B. International. 2011. Digital Distribution Maps of the Birds of the Western Hemisphere, version 4.0. Cambridge, UK: BirdLife International and Arlington, USA: NatureServe. 
Sauer, J.R., W.A. Link, J.E. Fallon, K.L. Pardieck, and D.J. Ziolkowski Jr. 2013. "The North American Breeding Bird Survey 1966-2011: Summary Analysis and Species Accounts." North American Fauna 79(79): 1-32.

Shaw, W.D., and J.B. Loomis. 2008. "Frameworks for Analyzing the Economic Effects of Climate Change on Outdoor Recreation." Climate Research 36(3): 259-269.

Sohl, T.L., K.L. Sayler, M.A. Bouchard, R.R. Reker, A.M. Friesz, S.L. Bennett, B.M. Sleeter, R. Sleeter, T. Wilson, C. Soulard, M. Knuppe, and T.V. Hofwegen 2014. "Spatially Explicit Modeling of 1992-2100 Land Cover and Forest Stand Age for the Conterminous United States." Ecological Applications 24(5): 1015-1036.

Steffen, W., P.J. Crutzen, and J.R. McNeill. 2007. "The Anthropocene: Are Humans Now Overwhelming the Great Forces of Nature." AMBIO: A Journal of the Human Environment 36(8): 614-621.

Steffen, W., J. Grinevald, P. Crutzen, and J. McNeill. 2011. “The Anthropocene: Conceptual and Historical Perspectives." Philosophical Transactions of the Royal Society of London A: Mathematical, Physical and Engineering Sciences 369(1938): 842-867.

Thomas, C.D., J.J. Lennon, et al. 1999. "Birds Extend Their Ranges Northwards." Nature 399 (6733): 213-213.

Train, K. 2009. Discrete Choice Methods with Simulation (Second edition). Cambridge University Press, Cambridge, UK.

U.S. EPA. 2016. "Climate Change Indicators in the United States." web page. Available at https://www.epa.gov/climate-indicators (accessed March 2016)

Voorheis, J. 2015. "MQtime: A Stata Tool for Calculating Travel Time and Distance Using MapQuest Web Services." Stata Journal 15(3), 845-853.

Wall, G. 1998. "Climate Change, Tourism and the IPCC." Tourism Recreation Research 23(2): 65-68.

Wiersma, Y.F. 2010. "Birding 2.0: Citizen Science and Effective Monitoring in the Web 2.0 World." Avian Conservation and Ecology 5(2), 13.

Zawacki, W.T., A. Marsinko, and J.M. Bowker. 2000. "A Travel Cost Analysis of Nonconsumptive Wildlife-Associated Recreation in the United States." Forest Science 46(4): 496-506. 